\title{
Interactions among drainage flows, gravity waves and turbulence: a BLLAST case study
}

\author{
C. Román-Cascón ${ }^{1}$, C. Yagüe ${ }^{1}$, L. Mahrt ${ }^{2}$, M. Sastre ${ }^{1}$, G.-J. Steeneveld ${ }^{3}$, E. Pardyjak ${ }^{4}$, A. van de Boer ${ }^{3}$, and \\ O. Hartogensis ${ }^{3}$ \\ ${ }^{1}$ Dept. de Geofísica y Meteorología, Universidad Complutense de Madrid, Madrid, Spain \\ ${ }^{2}$ NorthWest Research Associates, Corvallis, OR, USA \\ ${ }^{3}$ Meteorology and Air Quality Section, Wageningen University, Wageningen, the Netherlands \\ ${ }^{4}$ Department of Mechanical Engineering, University of Utah, Salt Lake City, UT, USA \\ Correspondence to: C. Román-Cascón (carlosromancascon@ucm.es)
}

Received: 20 March 2015 - Published in Atmos. Chem. Phys. Discuss.: 29 April 2015

Revised: 15 July 2015 - Accepted: 3 August 2015 - Published: 14 August 2015

\begin{abstract}
The interactions among several stable-boundarylayer (SBL) processes occurring just after the evening transition of 2 July 2011 have been analysed using data from instruments deployed over the area of Lannemezan (France) during the Boundary Layer Late Afternoon and Sunset Turbulence (BLLAST) field campaign. The near-calm situation of the afternoon was followed by the formation of local shallow drainage flows (SDFs) of less than $10 \mathrm{~m}$ depth at different locations. The SDF stage ended with the arrival of a stronger wind over a deeper layer more associated with the mountain-plain circulation, which caused mixing and destruction of the SDFs. Several gravity-wave-related oscillations were also observed on different time series. Wavelet analyses and wave parameters were calculated from high resolution and accurate surface pressure data of an array of microbarometers. These waves propagated relatively long distances within the SBL. The effects of these phenomena on turbulent parameters (friction velocity and kinematic heat flux) have been studied through multi-resolution flux decomposition methods performed on high frequency data from sonic anemometers deployed at different heights and locations. With this method, we were able to detect the different time-scales involved in each turbulent parameter and separate them from wave contributions, which becomes very important when choosing averaging-windows for surface flux computations using eddy covariance methods. The extensive instrumentation allowed us to highlight in detail the peculiarities of the surface turbulent parameters in the SBL, where several of the noted processes were interacting and producing
\end{abstract}

important variations in turbulence with height and between sites along the sloping terrain.

\section{Introduction}

A theoretical understanding of stable boundary layers (SBLs) is still an important and unachieved challenge (Mahrt, 2014), especially for numerical weather prediction (NWP) purposes (Van de Wiel et al., 2003; Baklanov et al., 2011; Seaman et al., 2012; Holtslag et al., 2013; Davy and Esau, 2014; Fernando et al., 2015). NWP models have problems representing SBLs (Holtslag et al., 2013; Steeneveld, 2014), which are related, for example, to the planetary boundary layer (PBL) evening transitions (Lapworth, 2015), minimum temperatures, low-level winds (Cuxart, 2008) and fog (Van der Velde et al., 2010; Román-Cascón et al., 2012) or air-quality (Andrén, 1990; Baklanov et al., 2009) forecasts. Among the reasons for these difficulties is the existence of the so-called submeso or submesoscale motions (Mahrt, 2009) that coexist with weak or very weak surface fluxes conditions (Mahrt et al., 2012). These motions (which include wave-like motions in the SBL) do not belong to the mesoscale nor to turbulent or micrometeorogical scales. They are usually defined as submeso motions (Mahrt, 2014), comprising scales of less than $2 \mathrm{~km}$, although this limit can be quite subjective. The separation (spectral gap) of these non-turbulent motions from turbulence is not always clear. Therefore, wrong estimations of surface turbu- 
lent fluxes are common in SBLs (Vickers and Mahrt, 2003; Voronovich and Kiely, 2007; Viana et al., 2009, 2012), especially over heterogeneous or complex terrain (Martínez et al., 2010; Seaman et al., 2012), where the interactions between local features and these phenomena complicate the analysis. The processes involved with the formation of these structures are hard to isolate, and the appearance of these motions is often sporadic and unexpected in many cases.

Some small-scale gravity waves (GWs) and drainage flows can be included in the submeso motions; they can significantly change the stable and typical conditions of calm and clear nights through the generation of intermittent turbulence in the SBL (Nappo, 1991; Sun et al., 2002, 2004, 2012; Van de Wiel et al., 2003; Mahrt, 2011, 2014; Vindel and Yagüe, 2011). They can also change the vertical and horizontal gradients of scalars and consequently the turbulent fluxes observed near surface. The theoretical study of these phenomena has been demonstrated to be very complex (Stull, 1988; Sorbjan, 1989; Fernando and Weil, 2010; Mahrt, 2014; Sun et al., 2015b), and some approximations done with laboratory experiments (Hopfinger, 1987; Riley and Lelong, 2000; Ohya et al., 2008) do not include troublesome factors of the real atmosphere. Therefore, the understanding of these processes through the observational analysis of real case studies becomes very important, especially when high-quality micrometeorological data are available for this purpose.

On the one hand, GWs are formed by buoyancy forces when air parcels are vertically displaced from their original equilibrium state (Nappo, 2012). They have been observationally analysed using different approaches (Ralph et al., 1997; Doyle and Durran, 2002; Viana et al., 2009, 2010, 2012; Sun et al., 2012; Román-Cascón et al., 2015a). All these studies illustrate the difficulties in determining the origin and formation mechanisms of GWs, their importance as sources of momentum and heat transport (Sukoriansky et al., 2009; Fernando and Weil, 2010) and the necessity of their accurate parameterization in NWP models (Fritts, 2003; Kim and Hong, 2009; Belušić and Mahrt, 2012; Nappo, 2012; Sun et al., 2015b).

However, detailed analyses of the impact of GWs on surface turbulence have received little attention in the literature (Viana et al., 2009; Sun et al., 2015b). In some cases, they have been shown to be structures that are effective at generating intermittent turbulence (Einaudi and Finnigan, 1993; Smedman et al., 1995; Román-Cascón et al., 2015a), while other studies highlight the important turbulence-suppressing effect that they can cause (Viana et al., 2009). In either case, the ubiquity of GWs in the SBL over a wide variety of scales (Belušić and Mahrt, 2012), and the presence of other turbulent and non-turbulent motions makes the study of these wave-turbulence interactions very complex (Belušić and Mahrt, 2008; Mahrt, 2009). As stated in Sun et al. (2015b), complete understanding of wave-turbulence interactions is an important challenge that yet remains elusive.
On the other hand, drainage flows are thermal circulations generated by the differential cooling between surface air masses in sloped or complex terrain under low synoptic forcing, when local conditions gain importance (Whiteman, 2000; Monti et al., 2002; Soler et al., 2002, 2014; Adachi et al., 2004). They are also typical SBL motions and manifest as sudden changes in wind direction, a temperature drop (due to the cooler current) or increasing winds at certain heights, among other effects (Yagüe et al., 2006; Viana et al., 2010; Udina et al., 2013). Several field campaigns have recently increased interest in these thermal circulations at different scales: e.g. METCRAX 2006 (Whiteman et al., 2008), COLPEX (Price et al., 2011), PCAPS (Lareau et al., 2013) or METCRAX II (Lehner et al., 2015b).

Drainage flow definitions include a wide range of possible spatial scales (Bossert and Cotton, 1994; Martínez et al., 2010). Katabatic and mountain-plain flows are mountainscale phenomena across and along valleys respectively, while density currents are usually associated with relatively flat terrain. Mountain breezes or katabatic winds (Whiteman, 2000) have been studied in many zones of the world (e.g. the Alps, Rotach et al., 2004; Nadeau et al., 2013, or Salt Lake Valley, Doran et al., 2002; Monti et al., 2002). However, shallow drainage flows (SDFs) or density currents have been less studied (Mahrt et al., 2001; Soler et al., 2002; Udina et al., 2013; Oldroyd et al., 2014; Lehner et al., 2015a), in part because of their smaller scale, that often makes them more difficult to detect. Their proximity to the surface and their ability to change the surface conditions make them important and interesting phenomena worthy of analysis in SBL studies.

This article deals with an SBL case study characterized by SDFs generated at different locations just after the near-calm situation of the evening transition during the Boundary Layer Late Afternoon and Sunset Turbulence (BLLAST) field campaign. These SDFs are later broken up by the arrival of a larger-scale and deeper mountain-plain wind, causing mixing among different layers close to the surface. At the same time, several wave-like oscillations were detected in different time series, related to the passage of GWs. Although these phenomena are common in SBLs, it is not easy to find clear evidence of their existence given the fine horizontal and vertical resolutions required for such observations. Thus, only a few studies have reported in detail cases like the one here presented, as for example in Sun et al. (2015a).

In this work we try to elucidate the physical mechanisms behind these evening transition processes, which was one of the goals of BLLAST campaign. Moreover, the analysis techniques employed to carry out this study have been shown to be appropriate for performing detailed studies of these local nocturnal-boundary-layer processes. Firstly, phase differences and wavelet analyses were performed on high-resolution pressure data from an array of microbarometers in order to analyse the detected GWs. Subsequently, a comparison of the effects of SDFs, mountain-plain winds and GWs over surface turbulence have been performed us- 
ing multi-resolution flux decomposition (MRFD) methods. The availability of several sonic anemometers at different sites and heights allowed us to explore the spatiotemporal behaviour of turbulence in detail. MRFD is also used to evaluate the relevant scales of turbulence and to separate them from larger-scales, like the observed GWs.

This paper is divided as follows: Sect. 2 explains in detail the BLLAST field campaign, the features and location of the instrumentation and the techniques employed to carry out the study; Sect. 3 presents results in several subsections; Sect. 4 summarises the article and highlights the more important results and conclusions, while also making recommendations for future studies.

\section{Data and methodology}

\subsection{BLLAST}

The BLLAST field campaign (Lothon et al., 2014) took place in Lannemezan $\left(43^{\circ} 07^{\prime} \mathrm{N}, 0^{\circ} 21^{\prime} \mathrm{E}, 600 \mathrm{~m}\right.$ above sea level, a.s.1.) and its surroundings from 14 June to 8 July 2011. The main objective was to study boundary-layer processes governing the late afternoon transition. The site is located on the plateau of Lannemezan, approximately $40 \mathrm{~km}$ North from the Pyrenees main massif, in a quite heterogeneous area (hilly with different land uses). Numerous international researchers deployed a dense array of meteorological instrumentation. Intense observational periods (IOPs) were identified as days with fair weather and weak synoptical forcing. On these days, additional measurements were performed: tethered balloons, aircrafts, unmanned aerial vehicles (UAVs) flights or extra soundings. A total of 12 IOPs resulted from the field campaign. The paper focuses on a case study corresponding to the 2 July 2011 (IOP 10), specifically the period corresponding from approximately $18: 00$ to 22:00 UTC. The observation of GWs, shallow flows and mountain-plain winds over these hours makes this day very interesting. Different sites with several research objectives and instrumentation were defined during the BLLAST field campaign around Lannemezan. Figure 1 shows an approximate location of the sites where instrumentation used in the present study was deployed. Table 1 is a summary with information about these sites and Table 2 specifies the instruments used at each site. Lothon et al. (2014) include a more detailed description of all these sites.

Drainage flows were mainly investigated at the divergence site (additionally at the micro and edge areas), while the GWs analysis from surface pressure records was mainly performed using high-resolution and accurate data from an array of three microbarometers deployed at the micro area. Finally, the analysis of surface turbulent parameters was investigated using data from sonic anemometers installed at different heights on an $8 \mathrm{~m}$ tower at the divergence site and at the edge area, which in turn was composed of three different sites (the wheat site, grass site and the border between these two sites, renamed "boundary site" in this study to avoid confusion).

\subsection{Methodology}

The relevant physical processes studied in this work have been analysed through the combination of several techniques applied to measurements from different instruments. Initial comparisons were made among time series of atmospheric variables from instrumentation located at several heights and locations. It is instructive to compare the behaviour of these records among sites because they can sometimes suggest some very local processes happening at a certain site but not at another. Moreover, more complex techniques have been applied and explained in the next three subsections.

\subsubsection{Wavelet and phase differences analyses}

Wavelet transforms are powerful spectral tools for the analysis of time series used in diverse scientific areas, especially in geophysics. In this study, they have been applied to surface pressure time series from three microbarometers. The results are very useful for detecting energy peaks during specific periods. This analysis can be used to identify coherent structures (GWs) when the energy increase remains almost constant for a specific range of periods and during a relatively long time interval. Descriptions of different wavelet transforms are numerous in the literature (Daubechies, 1992; Torrence and Compo, 1998). In this work we employ the Morlet wavelet, a complex function consisting of a plane wave modulated by a Gaussian function (Torrence and Compo, 1998; Cuxart et al., 2002; Viana et al., 2009).

Moreover, wave parameters (wavelength, phase speed and direction of propagation) have been evaluated using phase differences analysis (Terradellas et al., 2001; Viana et al., 2009). This method is based on the time differences observed in the wavelet spectral energy peaks of an atmospheric variable measured at least at three different sites at the surface. In this case, it has been applied over surface pressure time series of three PAROSCIENTIFIC (model 6000-16B) microbarometers (Cuxart et al., 2002), with accurately determined positions. These microbarometers were configured in a triangle with a separation of approximately $150 \mathrm{~m}$, sampling at a rate of $2 \mathrm{~Hz}$, which allowed a resolution of $0.002 \mathrm{hPa}$.

\subsubsection{Multi-resolution flux decomposition}

Multi-resolution flux decomposition (MRFD) (Howell and Mahrt, 1997; Vickers and Mahrt, 2003) is a multivariate and multiscale statistical tool based on the Haar transform (Haar, 1910). It represents a simple orthogonal decomposition whose spectra satisfy Reynolds averaging at every scale. It has been shown to be a powerful tool for turbulence studies, since it allows the separation of turbulent eddies from possible non-turbulent motions of larger scales when a spec- 

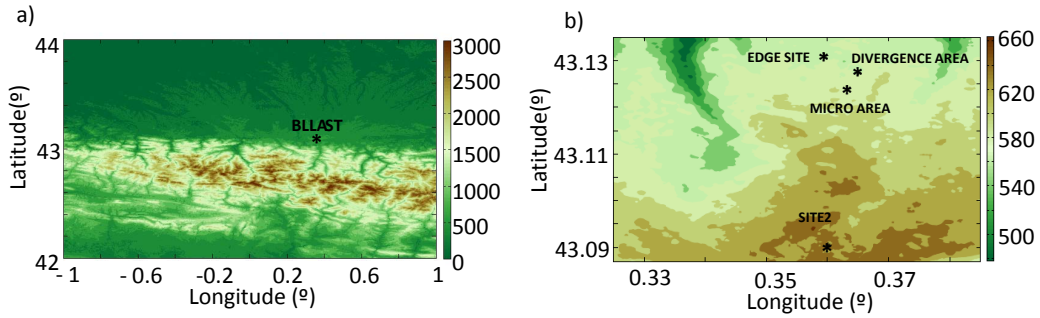

c)

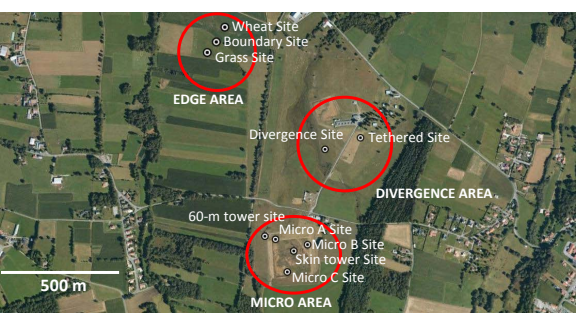

Figure 1. (a) Topographic map of Pyrenees area around BLLAST. (b) Topographic map of BLLAST area. (c) Aerial view of BLLAST sites (except area 2). NOTE - panels (a) and (b) from Routine ASTER Global Digital Elevation Model from NASA Land Processes Distributed Active Archive Center (LP DAAC). Panel (c) from Google Earth.

Table 1. Characteristics of BLLAST sites considered in this study.

\begin{tabular}{lllll}
\hline Super Area & Area & Site & Location & Height a.s.1. \\
\hline SUPER-AREA 1 & \multirow{2}{*}{ micro area } & micro A site & $43^{\circ} 07^{\prime} 26.8^{\prime \prime} \mathrm{N} 00^{\circ} 21^{\prime} 46.9^{\prime \prime} \mathrm{E}$ & $602 \mathrm{~m}$ \\
& & micro B site & $43^{\circ} 07^{\prime} 25.9^{\prime \prime} \mathrm{N} 00^{\circ} 21^{\prime} 53.1^{\prime \prime} \mathrm{E}$ & $600 \mathrm{~m}$ \\
& & micro C site & $43^{\circ} 07^{\prime} 22.2^{\prime \prime} \mathrm{N} 00^{\circ} 21^{\prime} 49.2^{\prime \prime} \mathrm{E}$ & $601 \mathrm{~m}$ \\
& & skin-tower site & $43^{\circ} 07^{\prime} 25.1^{\prime \prime} \mathrm{N} 00^{\circ} 21^{\prime} 50.4^{\prime \prime} \mathrm{E}$ & $600 \mathrm{~m}$ \\
& & $60 \mathrm{~m}$ tower Site & $43^{\circ} 07^{\prime} 27.1^{\prime \prime} \mathrm{N} 00^{\circ} 21^{\prime} 45.1^{\prime \prime} \mathrm{E}$ & $602 \mathrm{~m}$ \\
\cline { 2 - 5 } & \multirow{2}{*}{ divergence area } & divergence site & $43^{\circ} 07^{\prime} 39.1^{\prime \prime} \mathrm{N} 00^{\circ} 21^{\prime} 56.3^{\prime \prime} \mathrm{E}$ & $590 \mathrm{~m}$ \\
& & tethered site & $43^{\circ} 07^{\prime} 40.6^{\prime \prime} \mathrm{N} 00^{\circ} 22^{\prime} 03.1^{\prime \prime} \mathrm{E}$ & $594 \mathrm{~m}$ \\
\cline { 2 - 5 } & \multirow{2}{*}{ edge area } & grass site & $43^{\circ} 07^{\prime} 52.5^{\prime \prime} \mathrm{N} 00^{\circ} 21^{\prime} 33.9^{\prime \prime} \mathrm{E}$ & $582 \mathrm{~m}$ \\
& & wheat site & $43^{\circ} 07^{\prime} 56.1^{\prime \prime} \mathrm{N} 00^{\circ} 21^{\prime} 37.3^{\prime \prime} \mathrm{E}$ & $582 \mathrm{~m}$ \\
& & boundary site & $43^{\circ} 07^{\prime} 54.1^{\prime \prime} \mathrm{N} 00^{\circ} 21^{\prime} 35.6^{\prime \prime} \mathrm{E}$ & $582 \mathrm{~m}$ \\
\hline SUPER-AREA 2 & area 2 & corn site & $43^{\circ} 05^{\prime} 25.1^{\prime \prime} \mathrm{N} 00^{\circ} 21^{\prime} 29.6^{\prime \prime} \mathrm{E}$ & $646 \mathrm{~m}$ \\
& & moor site & $43^{\circ} 05^{\prime} 24.9^{\prime \prime} \mathrm{N} 00^{\circ} 21^{\prime} 42.6^{\prime \prime} \mathrm{E}$ & $646 \mathrm{~m}$ \\
\hline
\end{tabular}

tral gap (or minimum of energy of the spectrum) is well defined (van den Kroonenberg and Bange, 2007; Viana et al., 2009, 2010).

In Sect. 3.3, MRFD has been applied to time series of different magnitudes ( $u, v, w$ for the friction velocity (Eq. 1) and $w$ and $\theta$ for the kinematic heat flux $\left(\overline{w^{\prime} \theta^{\prime}}\right)$ ).

$u_{*}=\left[\left(-\overline{u^{\prime} w^{\prime}}\right)^{2}+\left(-\overline{v^{\prime} w^{\prime}}\right)^{2}\right]^{0.25}$

These time series are decomposed into averages of different timescales. The multi-resolution coefficients at every step of the sequence are interpreted as contributions to the total flux from the structures of the corresponding timescales. We work with temporal windows ranging from 0 to $13.6 \mathrm{~min}$ in duration with a 1 min overlap. Finally, a running mean of $3 \mathrm{~min}$ is applied over the obtained flux value, in order to smooth the final figures.

\subsubsection{WRF model}

Although the analysis presented in this study is mainly observational, the Weather Research and Forecasting (WRF-ARW v3.5.1) model has been used as a complement for the determination of the origin of the wind observed at 20:30 UTC, since this question could not be resolved solely with the available observational data.

The WRF model is a mesoscale NWP system used for operational and research purposes (Skamarock et al., 2008) which allows the use of several physical parameterizations. In this study, three two-way nested domains centred in Lannemezan (France) were used, with a horizontal resolution 
Table 2. Instrumentation used in each site.

\begin{tabular}{lll}
\hline Area & Site & Instruments \\
\hline Micro area & micro A site & microbarometer PAROSCIENTIFIC \\
& micro B site & microbarometer PAROSCIENTIFIC \\
micro C site & microbarometer PAROSCIENTIFIC \\
& skin-tower site & $8 \mathrm{~m}$ tower site (thermometers, wind vanes) \\
& $60 \mathrm{~m}$ tower site & $60 \mathrm{~m}$ tower site (thermometers, wind vanes) \\
\hline Divergence area & divergence site & $8 \mathrm{~m}$ tower (thermocouples, sonic anemometers) \\
& tethered site & tethered balloon (thermometers, wind vanes) \\
\hline Edge area & grass site & $8 \mathrm{~m}$ tower (thermometers, sonic anemometers and P from LI-7500) \\
& wheat site & $8 \mathrm{~m}$ tower (thermometers, sonic anemometers) \\
\hline Area 2 & boundary site & sonic anemometer \\
\hline
\end{tabular}

of 9, 3 and $1 \mathrm{~km}$ respectively and 50 vertically distributed terrain following eta levels. The model was initialized at 00:00 UTC of 2 July with NCEP-FNL (National Centers for Environmental Protection - final) operational global analysis data ( $1^{\circ}$ resolution). It ran for $30 \mathrm{~h}$ ( $6 \mathrm{~h}$ of spin up) with a time step of $30 \mathrm{~s}$. The Yonsei University scheme was used for the PBL parameterization and MM5 similarity for the surface layer scheme. The Noah Land Surface Model was used with input land use and soil category data from USGS. The rapid radiative transfer model (RRTM) and Dudhia schemes were selected for the representation of radiation (longwave and shortwave respectively) and the WRF single-moment 3class parameterization was used for the microphysics.

\section{Results and discussion}

\subsection{General analysis}

The 2 July 2011 was characterized by a weak surface pressure gradient over the south of France, which led to the predominance of light northerly winds during the afternoon (mixed stage in Fig. 2a) and a near-calm period approximately one hour before astronomical sunset, which occurred at 19:40 UTC. The wind speed decreased close to the surface around 18:55 UTC, with values below $0.5 \mathrm{~m} \mathrm{~s}^{-1}$ at the divergence site (Fig. 2a, near-calm stage). This site will be the reference site for the SDF analysis due to the availability of six sonic anemometers from 0.8 to $8 \mathrm{~m}$ above ground level (a.g.l.). This situation of near-calm is propitious for the appearance of surface drainage flows (SDFs) with a markedly SSE-SE component in the BLLAST area, which is the direction of most of the local slopes where the instrumentation of the field campaign were deployed. These density currents are caused by the differential cooling between near-surface air masses at different locations in sloped terrains. In particular, up to 4 days of the BLLAST field campaign showed SDFs after the near-calm period of the afternoon. The sharp
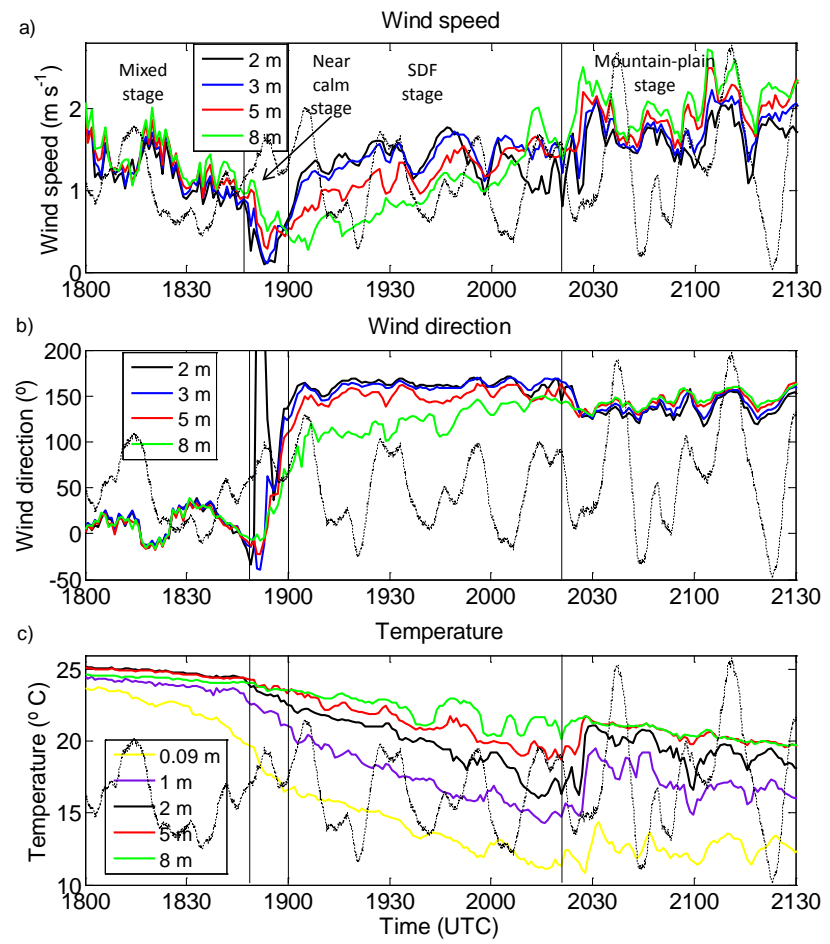

Figure 2. Time series from sonic anemometers and thermocouples measurements at the divergence site. (a) Wind speed $\left(\mathrm{m} \mathrm{s}^{-1}\right)$. (b) Wind direction $\left({ }^{\circ}\right)$. (c) Temperature $\left({ }^{\circ} \mathrm{C}\right)$. Note that filtered surface pressure from the micro A site is overlaid for reference with a thin dotted black line.

wind direction turning of this case study was well observed close to the surface at around 18:55 UTC (Fig. 2b) close to the surface, while measurements at higher heights (more than $8 \mathrm{~m}$ a.g.l., not shown) indicated a more gradual turning with time until 20:00-20:30 UTC. The wind direction veering near the surface was accompanied by a marked wind speed increase. Stronger winds were encountered at lower 

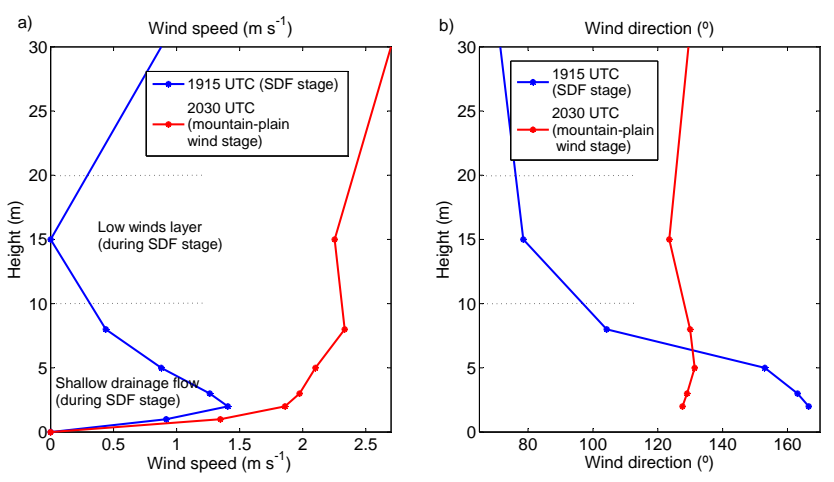

Figure 3. Wind speed (a) $\left(\mathrm{m} \mathrm{s}^{-1}\right)$ and wind direction (b) $\left(^{\circ}\right)$ vertical profiles during shallow drainage flow (SDF) stage at 19:15 UTC (blue line) and during mountain-plain wind stage at 20:30 UTC (red line). Measurements from the divergence site and $60 \mathrm{~m}$ tower site instruments.

levels with maxima close to the surface (around 2-3 m a.g.l.) and wind intensity decreasing with height. This is the clear picture of a slight SDF blowing from more elevated terrains to lower elevations in a layer close to the ground. The onset of this SDF coincides with the establishment of a surfacebased thermal inversion (Fig. 2c), although a more dramatic decrease in temperature is observed at the lowest levels approximately when the SDF arrives (18:40-19:00 UTC), as is expected when a cold density current appears. This decrease was especially noticeable at very low levels (below $1 \mathrm{~m}$ a.g.l.), which caused the enhancement of the temperature gradient between the ground and higher heights and the correspondent increase of stability close to the surface. The formed SDF was decoupled from the above flow by an upper low-wind layer and by the wind direction differences with height (blue line in Fig. 3). Nevertheless, surface heterogeneities and differences in local slopes between BLLAST sites led to differences in thickness and persistence of the SDFs from one location to another (Fig. 4), even blocking its formation at some places (as grass and wheat sites, both at the edge area) where these SDFs were poorly observed or lasted only for a few minutes.

The SDF stage ended between 20:00 and 20:30 UTC with the arrival of a stronger and deeper wind from SE (Fig. 2a and red line in Fig. 3, mountain-plain wind stage). This increase in wind was more noticeable at 45 and $60 \mathrm{~m}$ a.g.l. (not shown) and caused the breaking of the SDF and mixing (increase in temperature) at lower levels (Fig. 2c). The WRF model has been used to determine the origin and characteristics of this wind. Results from this mesoscale model simulation indicate that the wind was originated in the southerly located Pyrenees mountains and channelled through the valleys (not shown). The depth of this wind is shown in Fig. 5, where maximum in wind speed is observed around $80 \mathrm{~m}$ a.g.l. This is a clear indicator of the relatively shallow nature of this flow (compared to winds more related to synoptic scales). There-

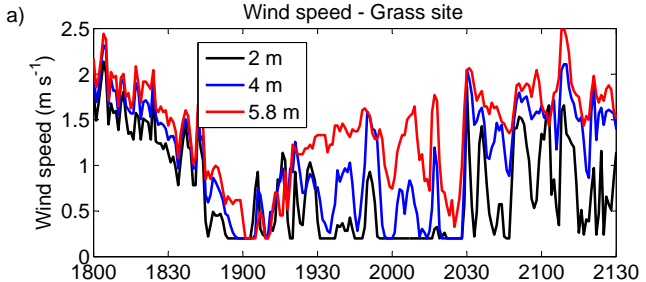

b)
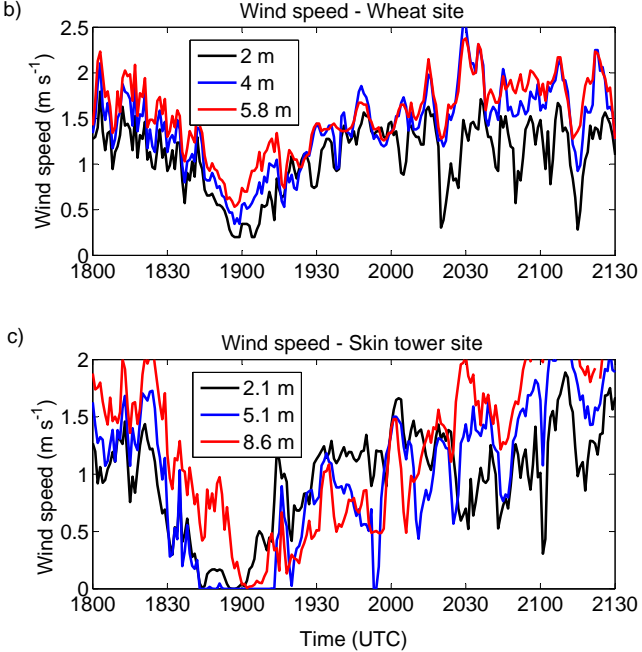

Figure 4. Wind speed $\left(\mathrm{m} \mathrm{s}^{-1}\right)$ measured at different heights at the grass site (a), wheat site (b) and skin-tower site (micro area) (c).

fore, SDFs were disrupted by the arrival of another drainage flow, deeper, stronger and with different characteristics than the former. However, the WRF simulation was neither able to resolve the SDFs nor the GWs observed during these periods.

\subsection{Pressure observations}

The previously described situation of decoupled layers in the lower PBL favours the formation of GWs generated by wind shear in a stable environment. The formation of the SBL around 18:00 UTC is characterized by an increase in the wave-like behaviour of the absolute and filtered pressure records from microbarometers (Fig. 6a, b). Regarding the filtered pressure, periods greater than $45 \mathrm{~min}$ have been removed (Fig. 6b) using a high-pass Butterworth filter, in order to avoid the pressure tendency and the diurnal cycle.

Two different events can be isolated from the energy increases observed in the wavelet analysis (Fig. 6c). The first one corresponds to almost four cycles of 20-25 min of period observed during the SDF stage (from 19:00 to 20:25 UTC approximately, red boxes in Fig. 6a-b). The second event is characterized by several oscillations of shorter periods with two notable cycles of greater amplitude from 20:30 to 21:30 UTC, i.e. after the destruction of the SDF by the arrival of the deeper wind (dashed purple boxes in Fig. 6a-b). Wave parameters for these wave-like structures have been evaluated using phase differences analysis (see Sect. 2.2.1) and 
Table 3. Gravity waves parameters evaluated from filtered surface pressure records of three microbarometers. Uncertainty is indicated inside brackets (range of values). Note how uncertainty is lower for wave event 2.

\begin{tabular}{llllll}
\hline & Time $(\mathrm{UTC})$ & Period $(\mathrm{min})$ & Wavelength $(\mathrm{km})$ & Phase speed $\left(\mathrm{m} \mathrm{s}^{-1}\right)$ & Direction of propagation $\left(^{\circ}\right)$ \\
\hline \multirow{2}{*}{ Wave event 1 } & $1925-2000$ & $20-25$ & not well defined & not well defined & not well defined \\
& $2005-2025$ & $22-24$ & {$[23-30]$} & {$[17-19]$} & {$[80-90]$} \\
\hline \multirow{2}{*}{ Wave event 2 } & $2035-2055$ & $10.5-12$ & {$[12-15]$} & {$[18-20]$} & {$[75-95]$} \\
& $2105-2130$ & $16-21$ & {$[7-10]$} & {$[6-9]$} & {$[32-42]$} \\
\hline
\end{tabular}

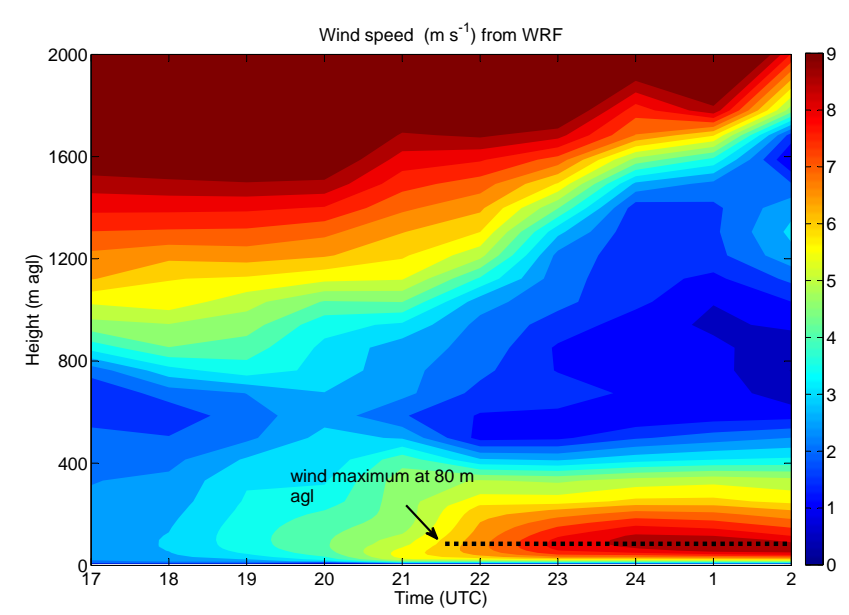

Figure 5. WRF wind speed $\left(\mathrm{ms}^{-1}\right)$ over Lannemezan from 17:00 UTC of 2 July to 02:00 UTC of 3 July from surface to $2000 \mathrm{~m}$ a.g.l. The results indicate the appearance of the mountainplain wind with maximum speed at around $80 \mathrm{~m}$ a.g.l.

are shown in Table 3. Both events are analysed in depth in the next subsections.

\subsubsection{Wave event 1 (19:00 to 20:25 UTC, SDF)}

Wave parameters have been evaluated from phase differences analysis (see Sect. 2.2.1), knowing the exact position of each microbarometer (Terradellas et al., 2001; Viana et al., 2009). This method is based on the differences between wave phases of the three filtered pressure records (one for each microbarometer). These differences are calculated for a determined time period and attending to different wave periods. Thus, for selected ranges of time and wave periods, we obtain specific ranges of wave parameters. The shorter this range of values is (for example for wavelength), the more monochromatic a wave is. This evaluation indicates that values for the first part of Event 1 are not well defined (Table 3, from 19:25 to 20:00 UTC), meaning that these oscillations are not clear enough due to the superimposition of other structures and motions, which is a common feature of the real atmosphere. Only the third cycle (from 20:05 to 20:25 UTC) shows a shorter range of wave parameters (Table 3), indicating clearer wave structures with well-defined parameters: direction of propagation from $\mathrm{W}$ towards $\mathrm{E}$, phase speed of around $18 \mathrm{~m} \mathrm{~s}^{-1}$ and approximate wavelength between 23 and $30 \mathrm{~km}$. On the other hand, all of these oscillations (cycles) of surface pressure were also observed at area 2 and at the edge area (Fig. 7), which were located respectively at $3.8 \mathrm{~km}$ (to the south) and $1 \mathrm{~km}$ (to the north) from the micro A site. The resolution and accuracy of the barometers (LI7500 barometers, except the microbarometers at the micro site) located at these sites were not the most appropriate to apply phase differences analysis. However, they were used to confirm that these wave-like oscillations were not confined to one specific place and that they were not limited to local SDFs, only observed at some places. Additionally, terrain height variance among sites (up to $70 \mathrm{~m}$ of difference between area 2 and the edge area, see Table 1) and the existence of some buildings and forests between sites indicate that the propagation of SDFs was perturbed, while the propagation of the wave-like motions in the pressure signals is clearly observed. With these outlines, the hypothesis that GWs are generated at the top or within the SDF is therefore discarded, while propagation of GWs in a deeper layer becomes more likely.

Figure $8 \mathrm{a}, \mathrm{b}$ shows vertical profiles of both wind speed and wind direction obtained from the combination of measurements from the descent of a tethered balloon from 19:52 to 19:58 UTC and tower measurements at 19:55 UTC. These profiles indicate a relatively strong wind shear not only at very shallow levels (as seen before due to the SDF), but also up to $100 \mathrm{~m}$ a.g.l., with winds blowing from S-SE at surface and from NE above $50 \mathrm{~m}$ a.g.l. Note also the slight low-level jet (LLJ) around $100 \mathrm{~m}$ a.g.l. The Brunt Väisälä (BV) frequency (Fig. 8d) has been calculated using temperature data from these sources (Fig. 8c) and it shows continuous stable conditions (SBLs) up to approximately $200 \mathrm{~m}$ a.g.l. This means that, theoretically, the GWs observed by the microbarometers could propagate from surface up to this height and are trapped in this layer.

It is difficult to explain the physical mechanism leading to the formation of the observed GWs with the available data, therefore, several hypotheses are offered. The first one is the intense wind shear (both in direction and speed of the wind) between layers in the lowest atmosphere. The convergence of SDFs from S-SE and the previous NE winds or the interaction of these shallow flows with the complex orography in a 

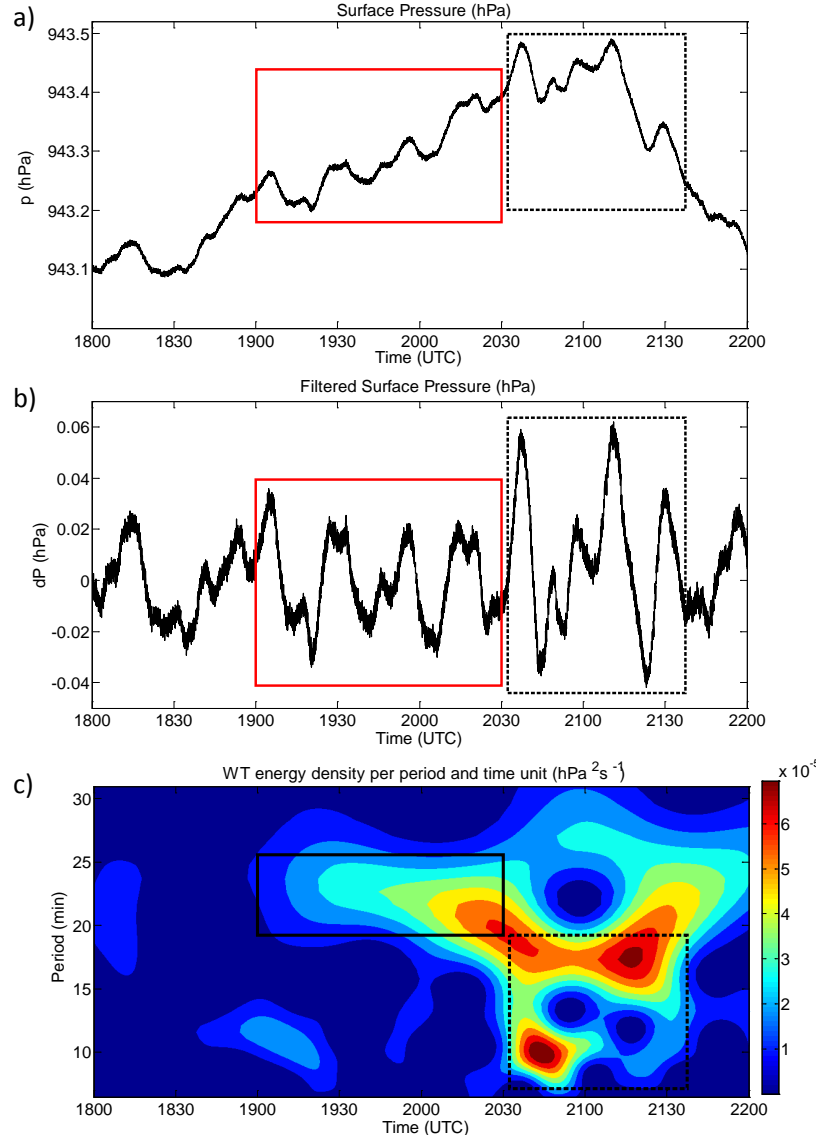

Figure 6. Absolute (a) and filtered (b) surface pressure (hPa) measured by microbarometer A. (c) Morlet wavelet-based energy density $\left(\mathrm{hPa}^{2} \mathrm{~s}^{-1}\right)$. Wave event 1 is indicated with red rectangles (black in c) and wave event 2 with dashed black rectangles. Note: these figures are almost identical for microbarometers B and C.

region located more to the south are other hypotheses for the GWs generation. Besides this, other factors such as the LLJ developed at $100 \mathrm{~m}$ a.g.l. could also be involved on the GWs generation.

Wave-related oscillations in other surface parameters (wind speed, wind direction and temperature) were also observed at all the locations (see Figs. 2 and 4), which indicate the effect of the GWs by alternating horizontal divergence and convergence patterns. Although the agreement between surface pressure and other parameters oscillations is quite good in some cases, linear polarization equations have been not applied to these records because of the existent difficulties when trying to isolate "clean" records in a real atmosphere like the case presented here. These difficulties have also been reported in other works (Nappo, 2012; Mahrt, 2014; Sun et al., 2015b).

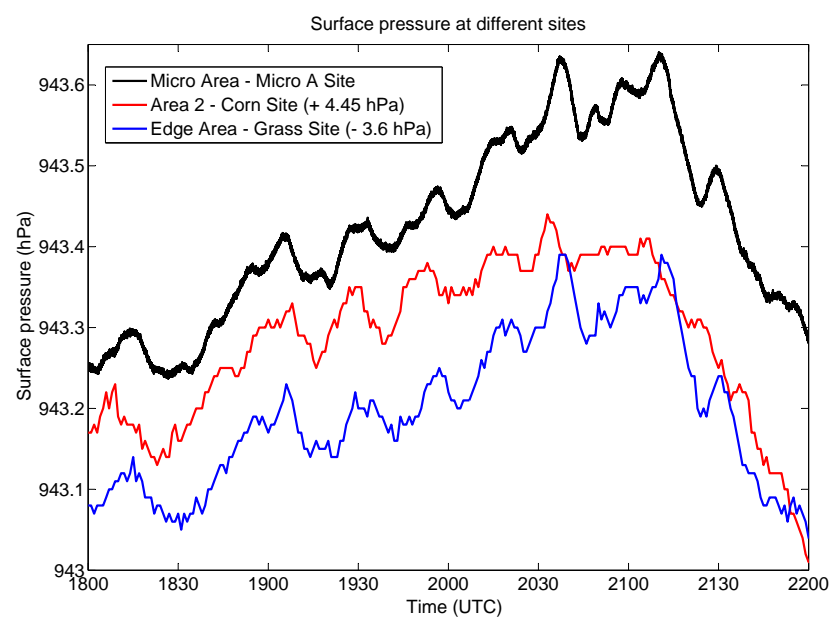

Figure 7. Absolute pressure (hPa) observed at three different sites of BLLAST: micro A site at the micro area (black line), the corn site at the SS2 area (red line, $3.8 \mathrm{~km} \mathrm{~S}$ from the micro A site) and the grass site at the edge area (blue line, $1 \mathrm{~km} \mathrm{NNW}$ from the micro A site). Note that 4.45 (3.6) hPa have been added (subtracted) to the original value at the corn site (grass site) in order to compare the figures.

\subsubsection{Wave event 2 (20:30 UTC onwards, mountain-plain wind)}

Evaluated parameters for the second wave event show differences compared to the first one. In this case, the event is characterized by values with little variation (Table 3), especially for the two noteworthy oscillations which caused the highest energy signal observed in the wavelet energy analysis. This indicates a clear propagation and an absence of perturbations from other motions. These surface pressure oscillations were also observed at sites separated more than $4 \mathrm{~km}$ (Fig. 7), which also gives an idea of their horizontal propagation.

The higher amplitudes observed in the surface pressure compared to wave event 1 could be due to changes in the depth of the duct layer or stable layer where the GWs were propagating (Román-Cascón et al., 2015a) (see also comment in Román-Cascón et al., 2015d). That is, the BruntVäisälä frequency vertical profile at this stage is likely different than the one shown in Fig. 8 (at 19:55 UTC), but this fact could not be checked due to the unavailability of tethered balloon or radio-sounding data after 20:00 UTC.

The oscillations observed in surface pressure from 20:35 UTC onwards are related to oscillations in other parameters, such as wind speed (Fig. 2a), wind direction (Fig. 2b) or temperature (Fig. 2c). The wind during this stage is characterized by a wave-like behaviour related to the passage of the GWs, as is observed when compared to filtered surface pressure records (dotted black line in Fig. 2a and b). Although the oscillations in wind speed have approximately the same period as the oscillations in pressure, the agreement 

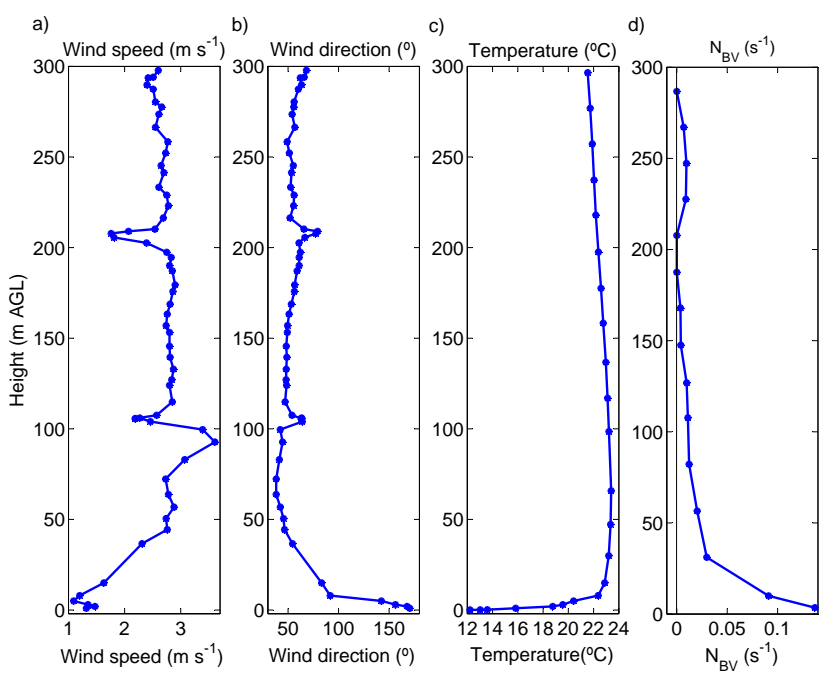

Figure 8. Vertical profiles considering combinations of measurements from $8 \mathrm{~m}$ tower measurements (from 1 to $8 \mathrm{ma.g.1.),} 60 \mathrm{~m}$ tower measurements (15 ma.g.l.) and the tethered balloon's descent measurements (from $30 \mathrm{~m}$ up to $300 \mathrm{~m}$ a.g.l.) approximately at 19:55 UTC. a) Wind speed $\left(\mathrm{m} \mathrm{s}^{-1}\right)$. (b) Wind direction $\left({ }^{\circ}\right)$. (c) Temperature $\left({ }^{\circ} \mathrm{C}\right)$. (d) Brunt Väisälä frequency $\left(\mathrm{N}_{\mathrm{BV}}\right)\left(\mathrm{s}^{-1}\right)$.

between maxima and minima of both variables is not constant, while the turning of wind speed due to the GWs is more obvious. In this case, maxima in surface pressure coincides with turnings of wind to the south and minima in pressure with turnings to the east direction. These oscillations have an approximate amplitude of $30-45^{\circ}$. Regarding temperature close to the surface, oscillations of several degrees of amplitude were also observed at different heights and sites (see for example Fig. $2 \mathrm{c}$ at the divergence site). These oscillations are again moderately correlated to surface pressure, as in wave event 1 . The variations in temperature and wind caused by the GWs at some levels led to a complex evolution of the gradients of these parameters with height, which in turn becomes very important for the surface fluxes and turbulence close to the surface, analysed in the next section.

\subsection{Surface turbulence: height differences}

The dependence of turbulent parameters on height has been analysed using sonic anemometers at three heights $(0.80,2$ and $8 \mathrm{ma}$ a.g.l.) installed in an $8 \mathrm{~m}$ tower at the divergence site. Large differences were observed in wind and temperature records between near-ground and upper levels (Fig. 2) during the studied period due to the microscale and local behaviour of the SDFs observed at some locations. The turbulent parameters were affected by these differences, and the general evolution shows several peculiarities which are analysed hereinafter through MRFD techniques.

For a clearer interpretation of Figs. 9 to 12, one must keep in mind that the $x$ axis shows the time in UTC and vertical axis indicates temporal scales, while the colour bar shows a)

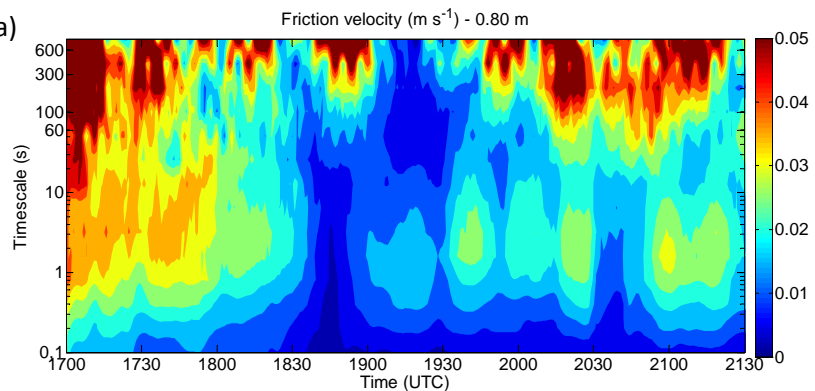

b)
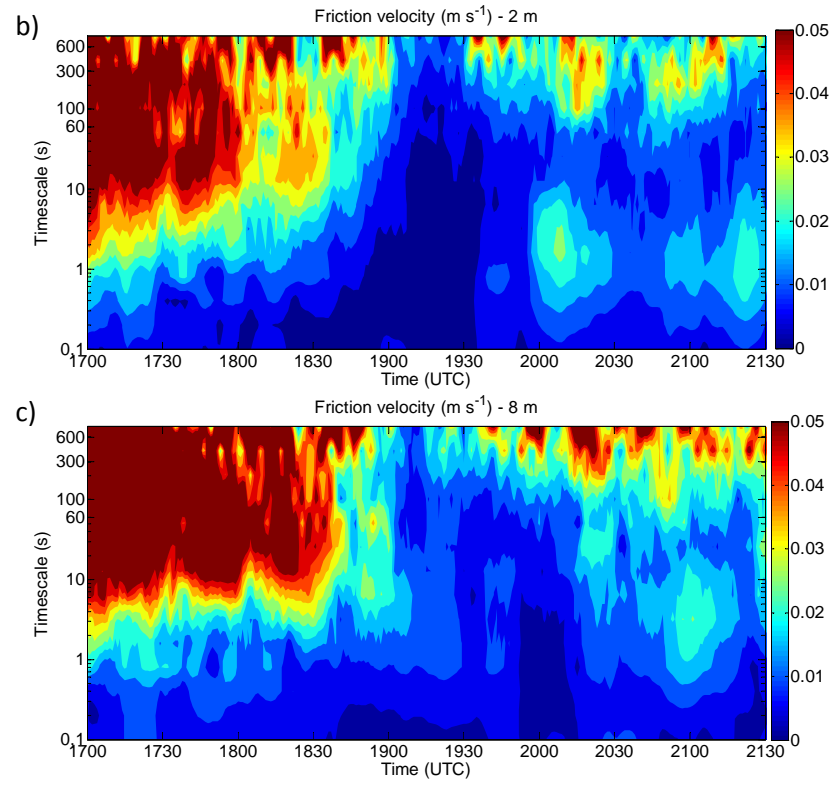

Figure 9. Multi-resolution flux decomposition (MRFD) of the friction velocity $\left(\mathrm{m} \mathrm{s}^{-1}\right)$ at $0.8 \mathrm{ma.g.l}$. (a), $2 \mathrm{ma.g.l}$. (b) and $8 \mathrm{~m}$ a.g.l. (c) at the divergence site.

the magnitude of the friction velocity or kinematic heat flux. Therefore, colours indicate the contribution of different temporal scales to the total value of each turbulent parameter.

\subsubsection{Friction velocity}

A wide range of temporal scales contributed to the friction velocity (Fig. 9) during the mixed stage (until 18:30 UTC approximately). However, the smallest scales (below $1 \mathrm{~s}$ ) were more predominant at $0.8 \mathrm{~m}$ a.g.1. than at $8 \mathrm{~m}$ a.g.l., due to the effect of the surface ground generating very small eddies. Moreover, larger scale eddies (from 10 to $800 \mathrm{~s}$ ) were more relevant at 2 and $8 \mathrm{~m}$ a.g.l.

The near-calm stage was especially noticeable at the lowest level $(0.8 \mathrm{~m}$ a.g.l. $)$, where a decrease for timescales below $200 \mathrm{~s}$ is clearly observed (around 18:45 UTC), as a consequence of the decrease in wind and stabilization of the layers very close to the ground. There is still an observed peak for contributions from larger scales (more than $300 \mathrm{~s}$ ), which is probably the result of larger eddies from the residual layer still present above. 
a)

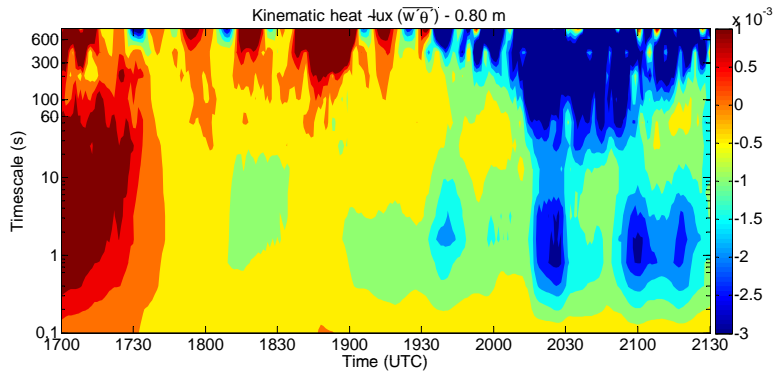

b)

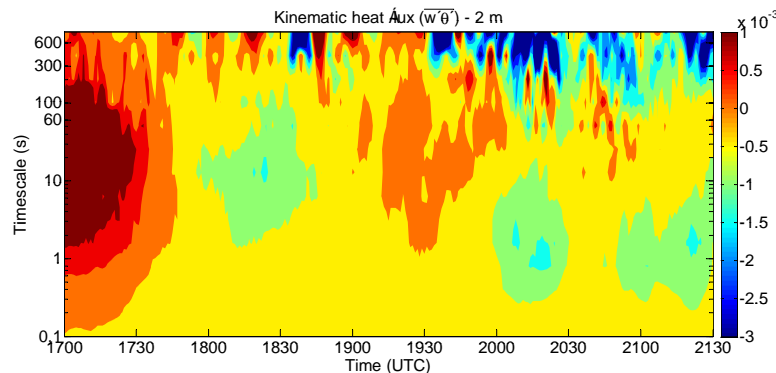

c)

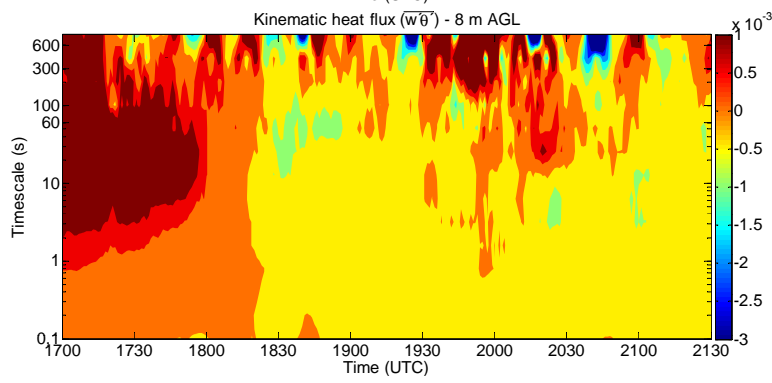

Figure 10. Multi-resolution flux decomposition (MRFD) of kinematic heat flux $\left(\mathrm{K} \mathrm{m} \mathrm{s}^{-1}\right)$ at $0.8 \mathrm{ma.g.1.} \mathrm{(a),} 2 \mathrm{ma.g.l}$. (b) and $8 \mathrm{~m}$ a.g.l. (c) at the divergence site.

The formation of the SDF after the near-calm stage (around 19:00 UTC) enhanced the turbulence very close to the surface $(0.8 \mathrm{~m}$ a.g.l.). However, friction velocity values remained very low for almost all scales at $2 \mathrm{~m}$ a.g.l. (SDF maximum of wind), while some turbulence is observed at $8 \mathrm{~m}$ a.g.l. This indicates the generation of turbulence by the SDF very close to the ground and above the shallow flow, but not in the middle of the flow (see also comment on RománCascón et al., 2015d). This is the result of the SDF wind profile (Fig. 3), with maximum around 2-3 ma.g.1. and with wind speed shear vanishing right at this maximum.

A wave-like pattern is also observed in the evolution at this stage; i.e. the friction velocity MRFD analysis shows alternating increases and decreases for scales between 0.5 and $20 \mathrm{~s}$, especially at $0.8 \mathrm{~m}$ a.g.l. (Fig. 9a). This pattern is associated with the GW-related oscillations seen in the wind speed time series.

The SDF wind shear from 2 to $8 \mathrm{ma}$ a.g.l. disappeared around 20:00 UTC, when wind speed at all levels converged to the same value. This is translated to an increase in the friction velocity at $2 \mathrm{~m}$ a.g.l., where the minimum was observed during the previous SDF stage. The decrease in wind shear
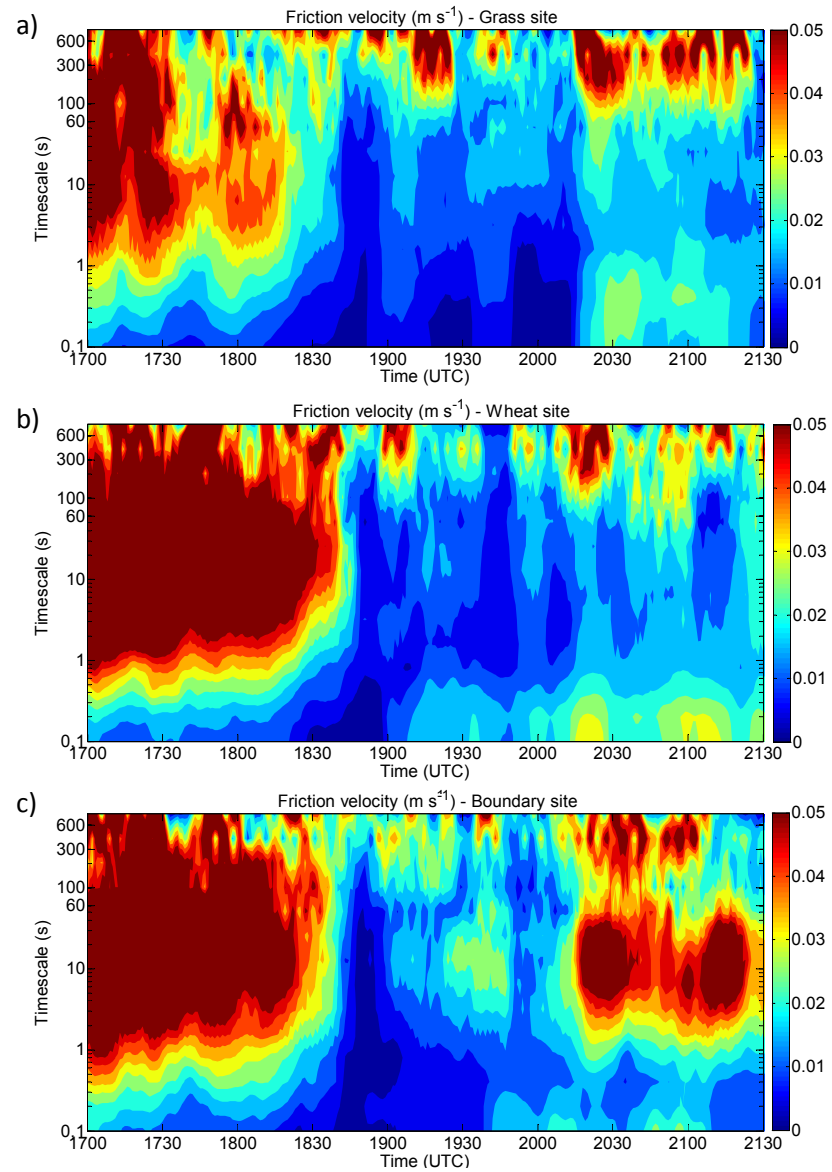

Figure 11. Multi-resolution flux decomposition (MRFD) of the friction velocity $\left(\mathrm{m} \mathrm{s}^{-1}\right)$ at grass (a), wheat (b) and boundary (c) sites (located at the edge area and at $2 \mathrm{~m}$ a.g.1.).

above $2 \mathrm{~m}$ a.g.l. also caused an observed decrease in turbulence at $8 \mathrm{~m}$ a.g.l. around 20:00 UTC. Later on, the arrival of the mountain-plain wind caused the complete destruction of the SDF, and the wind shear at low levels decreased considerably. In this case, the mountain-plain wind generated turbulence more effectively at all levels, without the clear minimum observed in the SDF stage.

Contributions to the friction velocity from larger scales are also observed from 19:30 UTC onwards, associated with the GWs analysed in Sect. 3.2.1. In this case, contributions from 60 to $800 \mathrm{~s}$ are separated from smaller scale turbulence (around $2 \mathrm{~s}$ ) by the spectral gap at 20-60 s approximately. That is, the absence of a continuous signal in the MRFD indicates that these contributions to the friction velocity are due to different mechanisms. Since wave scales are not supposed to contribute significantly to the turbulent mixing, these scales should not be included in a total flux calculation, and an averaging window of no more than 20 $60 \mathrm{~s}$ should be used during this period. However, there is still an open question about the possibility that some of these contributions to the friction velocity from scales between 60 to 
a)

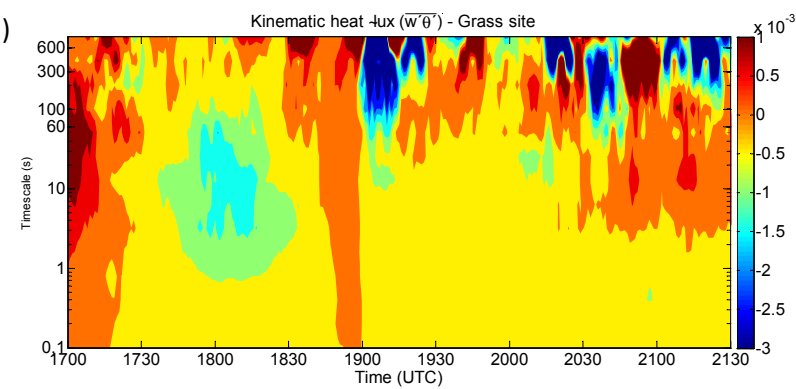

b)

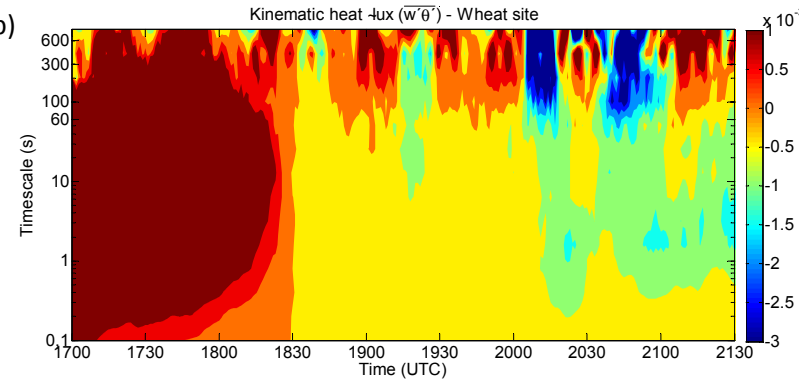

c)

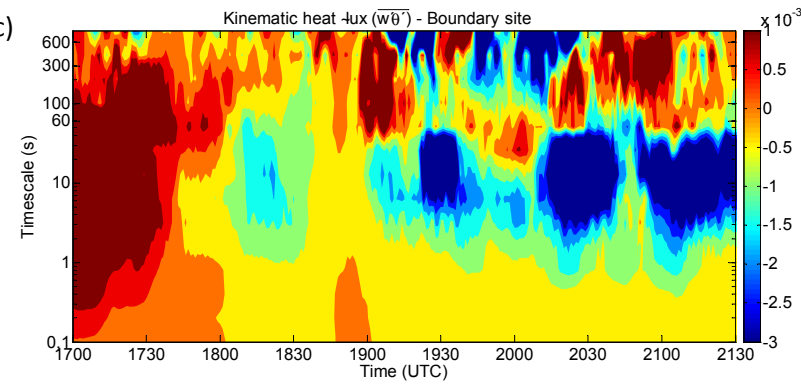

Figure 12. Multi-resolution flux decomposition (MRFD) of kinematic heat flux $\left(\mathrm{K} \mathrm{m} \mathrm{s}^{-1}\right)$ at grass (a), wheat (b) and boundary (c) sites (located at the edge area and at $2 \mathrm{~m}$ a.g.l.).

$800 \mathrm{~s}$ are in fact also turbulence, but are generated by the GWs themselves, in which case they should be included in a total turbulent flux calculation. In any case, the conclusions obtained from this case study and from this data set should not be applied to other data sets, due to the complexity of the studied event and local features (see comment in RománCascón et al., 2015c).

\subsubsection{Kinematic heat flux}

Kinematic heat flux at different heights (Fig. 10) changes from upwards to downwards at different times. This change happens first at the lower level and then more than half an hour later at $8 \mathrm{~m}$ a.g.l., as result of the progressive stabilization of the layers upwards from the surface. After this moment (and already with negative fluxes), there is an increase in the negative fluxes observed at 18:15 UTC, especially at 0.8 and $2 \mathrm{ma.g} .1$. and of scales between 1 and $100 \mathrm{~s}$ (green colours in Fig. 10a and b), as a consequence of the increase in the temperature gradient of the low levels. Later on, the kinematic heat flux magnitude decreases again (yellow colours in
Fig. 10), which is directly related to the strong decrease in wind speed during the near-calm period.

The SDF stage is characterized by an increase in the contribution of small scales (around $1 \mathrm{~s}$ ) to the surface kinematic heat flux very close to the ground (at $0.80 \mathrm{~m}$ a.g.l., green and blue colours in Fig. 10a from 19:00 to 20:00 UTC) due to the SDF-related increase in friction velocity seen in the previous section. However, at 2 and $8 \mathrm{~m}$ a.g.l., this stage is characterized by very low kinematic heat fluxes (near 0 , orange colours) because both temperature and wind gradients are smaller at these heights.

Considering the height of $0.8 \mathrm{~m}$ a.g.l. (Fig. 10a), it should be noted that the temporal scales (around $1 \mathrm{~s}$ ) contributing to the turbulence in this SDF period are smaller when compared to the scales observed before the arrival of the density current. The mean wind speed at $0.8 \mathrm{~m}$ a.g.l. (not shown) was of approximately $1 \mathrm{~m} \mathrm{~s}^{-1}$ from 18:00 to 18:30 UTC and of $1.5 \mathrm{~m} \mathrm{~s}^{-1}$ during the SDF stage (19:00 to 20:30 UTC). If we apply the frozen eddies hypothesis of Taylor (Stull, 1988) to convert temporal scales to length scales for both periods, we obtain approximate eddy sizes of 5 and $1.5 \mathrm{~m}$ respectively. In fact, the turbulence generated near surface due to the SDF is observed only in the lowest levels, but not at higher levels, while during the period previous to the near-calm situation (18:00 to 18:30 UTC), this increase in turbulence was also observed at $2 \mathrm{~m}$ a.g.l. and up to $5 \mathrm{~m}$ a.g.l. (not shown). The same can be concluded from friction velocity MRFD (Fig. 9) and it is indicative of the small eddies generated by the SDF by friction with the ground compared to the predominant eddies during low-winds-stable situations (period previous to the near-calm situation).

Finally, the arrival of the mountain-plain wind causes an increase in temperature at all levels except $8 \mathrm{~m}$ a.g.l. (Fig. 2c), meaning that the wind is causing mixing among the lowest levels and breaking the SDF. That is, air from aloft is brought to lower levels, and therefore the temperature increases, but this increase is progressive with height; it takes place sooner and it is more pronounced at higher heights, enhancing the temperature gradient between levels located very close to the ground. This fact and the increase in wind lead to an enhancement of the negative surface kinematic heat fluxes at $0.8 \mathrm{~m}$ a.g.l. (blue colours in Fig. 10a) at 20:15 UTC. However, the mixing at the highest level ( $8 \mathrm{~m}$ a.g.l.) causes the homogenization of the layer, and therefore the heat flux does not increase (Fig. 10c) at $8 \mathrm{~m}$ a.g.l. Later on, several increases and decreases in the heat flux are observed (especially at $0.80 \mathrm{~m}$ a.g.1.), corresponding to the wave-like behaviour of this period. As seen in the friction velocity MRFD, the turbulent scales are well separated from non-turbulent motions by a spectral gap around $10 \mathrm{~s}$. Again, the selection of a higher averaging window could cause an overestimation of the fluxes, since large scales could be associated with GWs. 


\subsection{Surface turbulence: site differences}

The difficulties estimating surface fluxes over heterogeneous terrain are well known, especially during very stable situations. In this section we compare the evolution of turbulent parameters through MRFD performed over measurements of three nearby sonic anemometers located at the so-called edge area. These instruments were strategically deployed on different land use sites and separated around $60 \mathrm{~m}$ among them, allowing us to analyse the effect of the different roughness lengths and land use over surface turbulence. These sonic anemometers were installed at $2 \mathrm{~m}$ a.g.l. over grass $(10 \mathrm{~cm}$ height approximately), wheat $(80 \mathrm{~cm}$ height approximately) and over the border between them. This border (boundary site) was composed by denser vegetation (harder) and a small ditch (see van de Boer et al., 2014, and comment on RománCascón et al., 2015c, for more information and figures about the edge area).

\subsubsection{Friction velocity}

The near-calm period is observed at all the places some minutes before 19:00 UTC but with slight differences in the starting time (Fig. 11). The SDF was not effectively formed at the edge area (see Fig. 4a, b), and therefore, a clear related increase in surface turbulence was neither observed at the grass site, nor at the wheat site. However, a certain increase in turbulence is observed at the boundary between these places (Fig. 11c from 19:00 to 19:45 UTC) that reveals the turbulence enhancement effect of this border.

The wind records at the grass site were clearly characterized by a wave-like behaviour during this stage with a maximum observed at the lowest levels (less than $5 \mathrm{~m}$ a.g.l.) around 19:30 UTC; this indicates an attempt of settling of some SDFs (see Fig. 4a). This increase in wind does not cause a direct increase in mechanical turbulence at the grass site (Fig. 11a), but it does it over the boundary site (Fig. 11c). This increase is possibly a consequence of the crash between a shallow flow from SE (from the grass site) and the denser and higher vegetation at the boundary site. Beyond this point (at the wheat site) this increase is again not observed, except for very small scales (below $1 \mathrm{~s}$ ). This fact is contrary to the processes observed at the grass site, where these small contributions were almost suppressed from 18:30 to 20:15 UTC, as a result of very low winds observed at the grass site during this period. These low winds observed at the grass site could be in turn affected by the maize field located upwind (to the south, see comment on Román-Cascón et al., 2015b).

With the arrival of the mountain-plain wind around 20:15 UTC, the turbulence slightly increases at the grass and wheat sites, while there is a marked increase at the boundary site (Fig. 11c), highlighting again the important effect of this obstacle between both places generating turbulence. In this stage, the very small-scale turbulence increase was observed at both sites, although it is more noticeable at the wheat site. The important increase in wind observed at the grass site some minutes before 20:30 UTC (Fig. 4a) is the cause of this enhancement observed in the friction velocity MRFD. However, reasons for the specific scale-contributions in this case are difficult to determine and are probably related to the roughness length of the different surfaces. It seems that unlike in the SDF stage, the grass roughness is acting efficiently in the generation of turbulence, mainly because of the important increase in wind speed observed at $2 \mathrm{~m}$ a.g.l. at 20:25 UTC (Fig. 4a), where the wind changes radically with the arrival of the mountain-plain wind.

Finally, the effects of the observed GWs are also present at all the sites, with important large-scale contributions for scales higher than $100 \mathrm{~s}$ and especially for scales of the order of minutes, as seen also before at the divergence site (Fig. 9). However, the GWs effects are not only observed over these large-scale contributions; there is a clear wave-like behaviour in turbulent scales (intermittent turbulence) during the whole period, with maximum followed by minimum contributions for all the involved scales. This is the result of the alternating horizontal divergence and convergence patterns of the SBL caused by the waves. That is, the oscillations observed in temperature and wind profiles at different heights are causing alternating increases and decreases in the temperature and wind gradients, which is consequently translated into these changes in surface fluxes.

\subsubsection{Kinematic heat flux}

Large differences have also been found among surface kinematic heat fluxes analysed at these three nearby but different places (Fig. 12). It is interesting to note that the kinematic heat flux changes from upward to downward considerably later at the wheat site than at the other sites. The wheat was drier in this season, and therefore the daytime convection is more intensive, and the decay takes longer. Consequently, the increase in negative surface kinematic fluxes due to the stabilization of the layer around 18:00 UTC at the other sites is not observed at the wheat site. The characteristics of the wheat canopy could also play a role limiting the effect of the radiative cooling by the wheat itself.

The near-calm period just before 19:00 UTC is well observed at all sites, especially at the grass site, where the diffusion of heat was almost completely suppressed for all scales. Later on, during the SDF stage, there is a tendency toward very small kinematic heat fluxes over wheat and grass surfaces (yellow colours), while an increase in the negative heat fluxes is observed at the edge between the sites (the boundary site, Fig. 12c), as also seen and explained in the previous section (greater friction velocity).

The consequences of the arrival of the mountain-plain wind are also very different depending on the site. Contrary to expected, a reduction of the surface fluxes is observed when the wind increases, and only small scales are contributing to diffuse the heat downward at the grass site (yellow 
colour below $3 \mathrm{~s}$ versus orange colour for contributions between 3 to $60 \mathrm{~s}$, from 20:15 UTC onwards). Although the mechanical turbulence slightly increased at this time (Fig. 11 at 20:15 UTC), the kinematic heat flux drop was probably caused by the mixing that occurred at higher levels, leading to a reduction of the temperature gradient. In contrast, the effect of the mountain-plain wind over the wheat site was to cause the enhancement of the negative kinematic heat fluxes, the explanation of which is hard to determine, since the temperature gradient behaviour was similar at the grass site (not shown).

The gap between turbulent and larger scales is very well defined at these sites during the whole period. There are clear alternations between positive and negative values (red and blue colours) of large scales, which is a distinctive characteristic of GWs (Viana et al., 2009, 2010). The spectral gap is especially well marked at the boundary site (Fig. 12c), where a change from negative (turbulence) to positive contributions (probably related to waves) is observed around $60 \mathrm{~s}$ from 19:00 UTC onwards. In this case, an inappropriate choice of the averaging interval when using eddy covariance methods to estimate turbulent parameters could lead to an important underestimation or even be the cause of the counter-gradient fluxes found sometimes in SBLs.

\section{Summary and conclusions}

Several stable-boundary-layer processes occurring along the afternoon and evening transition during the 2 July 2011 (IOP 10) of the BLLAST field campaign have been analysed in detail taking advantage of the large amount of accurate and high frequency instrumentation deployed over the area of Lannemezan (France).

Shallow drainage flows (SDFs) were formed just after the near-calm period of the afternoon at different locations due to small local slopes. The formation of these density currents led to untypical wind profiles, with maxima in wind speed around 2-3 $\mathrm{m}$ a.g.l., decreasing winds with height and marked changes in wind direction among different levels. These SDFs (not observed at all the sites due to heterogeneities of the area) were eroded by the arrival of a mountain-plain wind. This deeper wind was more associated with the scale of the Pyrenees and caused partial mixing and the establishment of new wind and temperature profiles.

Time series of pressure, wind and temperature showed a wave-like pattern during the SDFs stage and during the mountain-plain wind. The availability of precise and highfrequency data of surface pressure from an array of microbarometers allowed us to evaluate wave parameters, which indicated a shorter (more precise) range of values for gravity waves (GWs) parameters during the mountain-plain wind, with smaller wavelengths and phase speeds. These GWs were observed at different locations, indicating a non-local character and a clear propagation. Tethered balloons and tower measurements indicated stable stratification at least up to $200 \mathrm{~m}$ a.g.l., wind direction changing with height and even a weak LLJ around $100 \mathrm{~m}$ a.g.l. This wind shear or even the LLJ effects are proposed to be involved in the generation of these GWs, which in any case were trapped within the SBL. However, the effect of the nearby hilly terrain could also be important.

Finally, the effects of these different processes on the surface turbulent parameters (friction velocity and kinematic sensible heat flux) have been studied in detail using multi-resolution flux decomposition (MRFD) techniques from sonic anemometers data installed at different heights and sites. The microscale and shallow nature of some of these processes is underscored by the differences found at several heights. The selection of the height of the sensor could lead to underestimations of surface fluxes or turbulent parameters when density currents are present in very shallow layers, specially if sonic anemometers are located at the SDF windmaximum height (minimum in turbulence). The dependence of these turbulent parameters on the land-use and terrain is also highlighted through the comparison among the MRFD at the grass and wheat sites, and at the boundary between both sites.

MRFD is shown to be a powerful tool to determine the averaging-window needed to compute turbulent parameters or fluxes from the spectral gap observed between turbulent and larger-scale motions, as done in Nappo et al. (2008); Durden et al. (2013), where GWs scales are removed from the flux computation in order to avoid overestimation of fluxes. Otherwise, possibly wrong estimations of momentum (overestimation) and heat (overestimation, underestimation or even false counter-gradient) turbulent fluxes can be assumed. However, there is still an open question about the possible overlapping between wave scales and wave-generated turbulence (separated by a spectral gap from turbulence of smaller scales created by other mechanisms). In this case, part of these larger scales should be definitely included (Vercauteren and Klein, 2015), since their turbulent behaviour would contribute to the diffusion of scalars. These considerations must be taken into account, especially when analysing SBLs over heterogeneous terrain and during the evaluation of numerical models performance with field measurements.

Acknowledgements. This research has been funded by the Spanish Government (projects CGL2009-12797-C03-03, CGL2011-13477E and CGL2012-37416-C04-02). The BLLAST field experiment was made possible thanks to the contribution of several institutions and supports INSU-CNRS (Institut National des Sciences de l'Univers, Centre national de la Recherche Scientifique, LEFEIDAO program), Météo-France, Observatoire Midi-Pyrénées (University of Toulouse), EUFAR (EUropean Facility for Airborne Research) and COST ES0802 (European Cooperation in the field of Scientific and Technical). The field experiment would not have occurred without the contribution of all participating European and American research groups, which all have contributed significantly. 
BLLAST field experiment was hosted by the instrumented site of Centre de Recherches Atmosphériques, Lannemezan, France (Observatoire Midi-Pyrénées, Laboratoire d'Aérologie). BLLAST data are managed by SEDOO, from Observatoire Midi-Pyrénées. The tower equipment was supported by CNRS, University of Toulouse and European POCTEFA FluxPyr program and FEDER program (Contract 34172 - IRENEA - ESPOIR). The corn and moor stations were funded by the CNRS INSU and Météo-France and implemented by the CNRM-GAME team GMEI/4M. The edge site measurements were financed by the DFG (Deutsche Forschungsgemeinschaft) project GR2687/3-1 and SCHU2350/2-1. Gert-Jan Steeneveld contribution was supported by the NWOVENI grant 863.10.010.

Edited by: R. J. Beare

\section{References}

Adachi, A., Clark, W. L., Hartten, L. M., Gage, K. S., and Kobayashi, T.: An observational study of a shallow gravity current triggered by katabatic flow, Ann. Geophys., 22, 3937-3950, doi:10.5194/angeo-22-3937-2004, 2004.

Andrén, A.: Evaluation of a turbulence closure scheme suitable for air-pollution applications, J. Appl. Meteorol., 29, 224-239, 1990.

Baklanov, A. A., Grisogono, B., Bornstein, R., Mahrt, L., Zilitinkevich, S. S., Taylor, P., Larsen, S. E., Rotach, M. W., and Fernando, H.: The nature, theory, and modeling of atmospheric planetary boundary layers, B. Am. Meteorol. Soc., 92, 123-128, 2011.

Baklanov, A. A., Grimmond, S., Mahura, A., and Athanassiadou, M.: Meteorological and Air Quality Models for Urban Areas, Springer, 140 pp., 2009.

Belušić, D. and Mahrt, L.: Estimation of length scales from mesoscale networks, Tellus, A, 60, 706-715, doi:10.1111/j.16000870.2008.00328.x, 2008.

Belušić, D. and Mahrt, L.: Is geometry more universal than physics in atmospheric boundary layer flow?, J. Geophys. Res.-Atmos., 117, 2156-2202, doi:10.1029/2011JD016987, 2012.

Bossert, J. E. and Cotton, W. R.: Regional-scale flows in mountainous terrain. Part 1: A numerical and observational comparison, Mon. Weather Rev., 122, 1449-1471, doi:10.1175/15200493(1994)122<1449:RSFIMT>2.0.CO;2, 1994.

Cuxart, J.: Nocturnal basin low-level jets: an integrated study, Acta Geophys., 56, 100-113, doi:10.2478/s11600-007-0042-2, 2008.

Cuxart, J., Morales, G., Terradellas, E., and Yagüe, C.: Study of coherent structures and estimation of the pressure transport terms for the nocturnal stable boundary layer, Bound.-Lay. Meteorol., 105, 305-328, doi:10.1023/A:1019974021434, 2002.

Daubechies, I.: Ten lectures on wavelets, Vol. 61, Society for Industrial and Applied Mathematics (SIAM), Capital City Press, Philadelphia, 354 pp., 1992.

Davy, R. and Esau, I.: Global climate models' bias in surface temperature trends and variability, Environ. Res. Lett., 9, 114024, doi:10.1088/1748-9326/9/11/114024, 2014.
Doran, J. C., Fast, J. D., and Horel, J.: The VTMX 2000 campaign, B. Am. Meteorol. Soc., 83, 537-551, doi:10.1175/15200477(2002)083<0537:TVC>2.3.CO;2, 2002.

Doyle, J. D. and Durran, D. R.: The Dynamics of Mountain-WaveInduced Rotors, J. Atmos. Sci., 59, 186-201, doi:10.1175/15200469(2002)059<0186:TDOMWI>2.0.CO;2, 2002.

Durden, D. J., Nappo, C. J., Leclerc, M. Y., Duarte, H. F., Zhang, G., Parker, M. J., and Kurzeja, R. J.: On the impact of wavelike disturbances on turbulent fluxes and turbulence statistics in nighttime conditions: a case study, Biogeosciences, 10, 84338443, doi:10.5194/bg-10-8433-2013, 2013.

Einaudi, F. and Finnigan, J. J.: Wave-turbulence dynamics in the stably stratifies boundary layer, J. Atmos. Sci., 50, 1841-1864, doi:10.1175/1520-0469(1993)050<1841:WTDITS >2.0.CO;2, 1993.

Fernando, H., Pardyjak, E., Sabatino, S. D., Chow, F., Wekker, S. D., Hoch, S., Hacker, J., Pace, J., Pratt, T., Pu, Z., Steenburgh, W., Whiteman, C., Wang, Y., Zajic, D., Balsley, B., Dimitrova, R., Emmitt, G., Higgins, C., Hunt, J., Knievel, J., Lawrence, D., Liu, Y., Nadeau, D., Kit, E., Blomquist, B., Conry., P., Coppersmith, R., Creegan, E., Felton, M., Grachev, A., Gunawardena, N., Hang, C., Hocut, C., Huynh, G., Jeglum, M., Jensen, D., Kulandaivelu, V., Lehner, M., Leo, L., Liberzon, D., Massey, J., McEnerney, K., Pal, S., Price, T., Sghiatti, M., Silver, Z., Thompson, M., Zhang, H., and Zsedrovits, T.: THE MATERHORN Unraveling the Intricacies of Mountain Weather, B. Am. Meteorol. Soc., doi:10.1175/BAMS-D-13-00131.1, online first, 2015.

Fernando, H. J. S. and Weil, J. C.: Whither the stable boundary layer?, B. Am. Meteorol. Soc., 91, 1475-1484, doi:10.1175/2010BAMS2770.1, 2010.

Fritts, D. C.: Gravity wave dynamics and effects in the middle atmosphere, Rev. Geophys., 41, 1003, doi:10.1029/2001RG000106, 2003.

Haar, A.: Zur Theorie der orthogonalen Funktionensysteme (On the theory of orthogonal function systems), Math. Ann., 69, 331371, 1910.

Holtslag, A. A. M., Svensson, G., Baas, P., Basu, S., Beare, B., Beljaars, A. C. M., Bosveld, F. C., Cuxart, J., Lindvall, J., Steeneveld, G. J., Tjernström, M., and Van De Wiel, B. J. H.: Stable atmospheric boundary layers and diurnal cycles: challenges for weather and climate models, B. Am. Meteorol. Soc., 94, 16911706, 2013.

Hopfinger, E.: Turbulence in stratified fluids: a review, J. Geophys. Res., 92, 5287-5303, doi:10.1029/JC092iC05p05287, 1987.

Howell, J. and Mahrt, L.: Multiresolution flux decomposition, Bound.-Lay. Meteorol., 83, 117-137, doi:10.1023/A:1000210427798, 1997.

Kim, Y. J. and Hong, S. Y.: Interaction between the orographyinduced gravity wave drag and boundary layer processes in a global atmospheric model, Geophys. Res. Lett., 36, 19-23, doi:10.1029/2008GL037146, 2009.

Lapworth, A.: Observations of the site dependency of the morning wind and the role of gravity waves in the transitions, Q. J. Roy. Meteorol. Soc., 141, 27-36, doi:10.1002/qj.2340, 2015.

Lareau, N. P., Crosman, E., Whiteman, C. D., Horel, J. D., Hoch, S. W., Brown, W. O., and Horst, T. W.: The persistent cold-air pool study, B. Am. Meteorol. Soc., 94, 51-63, 2013. 
Lehner, M., Whiteman, C., Hoch, S., Jensen, D., Pardyjak, E., Leo, L., Di Sabatino, S., and Fernando, H.: A case study of the nocturnal boundary-layer evolution on a slope at the foot of a desert mountain, J. Appl. Meteorol. Clim., 54, 732-751, doi:10.1175/JAMC-D-14-0223.1, 2015a.

Lehner, M., Whiteman, C. D., Hoch, S. W., Crosman, E. T., Jeglum, M. E., Cherukuru, N. W., Calhoun, R., Adler, B., Kalthoff, N., Rotunno, R., Horst, T., Semmer, S., Brown, W., Oncley, S., Vogt, R., Grudzielanek, M., Cermak, J., Fonteyne, N., Bernhofer, C., Pitacco, A., and Klein, P.: The METCRAX II field experimentA study of downslope windstorm-type flows in Arizona's Meteor Crater, B. Am. Meteorol. Soc., doi:10.1175/BAMS-D-1400238.1, online first, 2015b.

Lothon, M., Lohou, F., Pino, D., Couvreux, F., Pardyjak, E. R., Reuder, J., Vilà-Guerau de Arellano, J., Durand, P, Hartogensis, O., Legain, D., Augustin, P., Gioli, B., Lenschow, D. H., Faloona, I., Yagüe, C., Alexander, D. C., Angevine, W. M., Bargain, E, Barrié, J., Bazile, E., Bezombes, Y., Blay-Carreras, E., van de Boer, A., Boichard, J. L., Bourdon, A., Butet, A., Campistron, B., de Coster, O., Cuxart, J., Dabas, A., Darbieu, C., Deboudt, K., Delbarre, H., Derrien, S., Flament, P., Fourmentin, M., Garai, A., Gibert, F., Graf, A., Groebner, J., Guichard, F., Jiménez, M. A., Jonassen, M., van den Kroonenberg, A., Magliulo, V., Martin, S., Martinez, D., Mastrorillo, L., Moene, A. F., Molinos, F., Moulin, E., Pietersen, H. P., Piguet, B., Pique, E., RománCascón, C., Rufin-Soler, C., Saïd, F., Sastre-Marugán, M., Seity, Y., Steeneveld, G. J., Toscano, P., Traullé, O., Tzanos, D., Wacker, S., Wildmann, N., and Zaldei, A.: The BLLAST field experiment: Boundary-Layer Late Afternoon and Sunset Turbulence, Atmos. Chem. Phys., 14, 10931-10960, doi:10.5194/acp14-10931-2014, 2014.

Mahrt, L.: Characteristics of submeso winds in the stable boundary layer, Bound.-Lay. Meteorol., 130, 1-14, doi:10.1007/s10546008-9336-4, 2009.

Mahrt, L.: Surface wind direction variability, J. Appl. Meteorol. Clim., 50, 144-152, doi:10.1175/2010JAMC2560.1, 2011.

Mahrt, L.: Stably Stratified Atmospheric Boundary Layers, Annu. Rev. Fluid Mech., 46, 23-45, doi:10.1146/annurev-fluid-010313141354, 2014.

Mahrt, L., Vickers, D., Nakamura, R., Soler, M. R., Sun, J., Burns, S., and Lenschow, D. H.: Shallow drainage flows, Bound.-Lay. Meteorol., 101, 243-260, doi:10.1023/A:1019273314378, 2001.

Mahrt, L., Richardson, S., Seaman, N., and Stauffer, D.: Turbulence in the nocturnal boundary layer with light and variable winds, Q. J. Roy. Meteorol. Soc., 138, 1430-1439, doi:10.1002/qj.1884, 2012.

Martínez, D., Jiménez, M. A., Cuxart, J., and Mahrt, L.: Heterogeneous Nocturnal Cooling in a Large Basin Under Very Stable Conditions, Bound.-Lay. Meteorol., 137, 97-113, doi:10.1007/s10546-010-9522-z, 2010.

Monti, P., Fernando, H. J. S., Princevac, M., Chan, W. C., Kowalewski, T. A., and Pardyjak, E. R.: Observations of Flow and Turbulence in the Nocturnal Boundary Layer over a Slope, J. Atmos. Sci., 59, 2513-2534, doi:10.1175/15200469(2002)059<2513:OOFATI>2.0.CO;2, 2002.

Nadeau, D. F., Pardyjak, E. R., Higgins, C. W., Huwald, H., and Parlange, M. B.: Flow during the evening transition over steep Alpine slopes, Q. J. Roy. Meteorol. Soc., 139, 607-624, doi:10.1002/qj.1985, 2013.
Nappo, C. J.: Sporadic breakdown of stability in the PBL over simple and complex terrain, Bound.-Lay. Meteorol., 54, 69-87, doi:10.1007/BF00119413, 1991.

Nappo, C. J.: An introduction to atmospheric gravity waves, 2nd Edn., Vol.102, Academic Press, 2012.

Nappo, C. J., Miller, D., and Hiscox, A.: Wave-modified flux and plume dispersion in the stable boundary layer, Bound.-Lay. Meteorol., 129, 211-223, 2008.

Ohya, Y., Nakamura, R., and Uchida, T.: Intermittent bursting of turbulence in a stable boundary layer with low-level jet, Bound.Lay. Meteorol., 126, 349-363, doi:10.1007/s10546-007-9245-y, 2008.

Oldroyd, H. J., Katul, G., Pardyjak, E. R., and Parlange, M. B.: Momentum balance of katabatic flow on steep slopes covered with short vegetation, Geophys. Res. Lett., 41, 4761-4768, doi:10.1002/2014GL060313, 2014.

Price, J., Vosper, S., Brown, A., Ross, A., Clark, P., Davies, F., Horlacher, V., Claxton, B., McGregor, J., Hoare, J., Jemmett-Smith, B., and Sheridan, P.: COLPEX: field and numerical studies over a region of small hills, B. Am. Meteorol. Soc., 92, 1636-1650, 2011.

Ralph, F. M., Neiman, P. J., Keller, T. L., Levinson, D., and Fedor, L.: Observations, Simulations, and Analysis of Nonstationary Trapped Lee Waves, J. Atmos. Sci., 54, 1308-1333, doi:10.1175/1520-0469(1997)054<1308:OSAAON>2.0.CO;2, 1997.

Riley, J. J. and Lelong, M.-P.: Fluid motions in the presence of strong stable stratification, Annu. Rev. Fluid Mech., 32, 613-657, doi:10.1146/annurev.fluid.32.1.613, 2000.

Román-Cascón, C., Yagüe, C., Sastre, M., Maqueda, G., Salamanca, F., and Viana, S.: Observations and WRF simulations of fog events at the Spanish Northern Plateau, Adv. Sci. Res., 8, 11-18, doi:10.5194/asr-8-11-2012, 2012.

Román-Cascón, C., Yagüe, C., Viana, S., Sastre, M., Maqueda, G., Lothon, M., and Gomara, I.: Near monochromatic ducted gravity waves associated with a convective sytem close to the Pyrenées, Q. J. R. Meteorol. Soc., 141, 1320-1332, doi:10.1002/qj.2441, 2015a.

Román-Cascón, C., Yagüe, C., Mahrt, L., Sastre, M., Steeneveld, G., Pardyjak, E., van de Boer, A., and Hartogensis, O.: Interactive comment on "Interactions among drainage flows, gravity waves and turbulence: a BLLAST case study" by C. Román-Cascón et al., Atmos. Chem. Phys. Discuss., 15, C3759-C3759, 2015 b.

Román-Cascón, C., Yagüe, C., Mahrt, L., Sastre, M., Steeneveld, G., Pardyjak, E., van de Boer, A., and Hartogensis, O.: Interactive comment on "Interactions among drainage flows, gravity waves and turbulence: a BLLAST case study" by C. Román-Cascón et al., Atmos. Chem. Phys. Discuss., 15, C3760-C3760, 2015 c.

Román-Cascón, C., Yagüe, C., Mahrt, L., Sastre, M., Steeneveld, G., Pardyjak, E., van de Boer, A., and Hartogensis, O.: Interactive comment on "Interactions among drainage flows, gravity waves and turbulence: a BLLAST case study" by C. Román-Cascón et al., Atmos. Chem. Phys. Discuss., 15, C3761-C3761, 2015 d.

Rotach, M. W., Calanca, P., Graziani, G., Gurtz, J., Steyn, D. G., Vogt, R., Andretta, M., Christen, A., Cieslik, S., Connolly, R., De Wekker, S. F. J., Galmarini, S., Kadygrov, E. N., Kadygrov, V., Miller, E., Neininger, B., Rucker, M., Van Gorsel, E., Weber, H., Weiss, A., and Zappa, M.: Turbulence structure and exchange 
processes in an Alpine Valley: The Riviera Project, B. Am. Meteorol. Soc., 85, 1367-1385, doi:10.1175/BAMS-85-9-1367, 2004.

Seaman, N. L., Gaudet, B. J., Stauffer, D. R., Mahrt, L., Richardson, S. J., Zielonka, J. R., and Wyngaard, J. C.: Numerical Prediction of Submesoscale Flow in the Nocturnal Stable Boundary Layer over Complex Terrain, Mon. Weather Rev., 140, 956-977, doi:10.1175/MWR-D-11-00061.1, 2012.

Skamarock, W., Klemp, J., Dudhi, J., Gill, D., Barker, D., Duda, M., Huang, X.-Y., Wang, W., and Powers, J.: A Description of the Advanced Research WRF Version 3, Tech. Rep., p. 113, doi:10.5065/D6DZ069T, 2008.

Smedman, A.-S., Bergström, H., and Högström, U.: Spectra, variances and length scales in a marine stable boundary layer dominated by a low level jet, Bound.-Lay. Meteorol., 76, 211-232, doi:10.1007/BF00709352, 1995.

Soler, M., Infante, C., Buenestado, P., and Mahrt, L.: Observations of nocturnal drainage flows in a shallow gully, Bound.-Lay. Meteorol., 105, 253-273, doi:10.1023/A:1019910622806, 2002.

Soler, M. R., Udina, M., and Ferreres, E.: Observational and Numerical Simulation Study of a Sequence of Eight Atmospheric Density Currents in Northern Spain, Bound.-Lay. Meteorol., 153, 195-216, doi:10.1007/s10546-014-9942-2, 2014.

Sorbjan, Z.: Structure of the Atmospheric Boundary Layer, Prentice Hall, Englewood Cliffs, 317 pp., New Jersey, 1989.

Steeneveld, G.-J.: Current challenges in understanding and forecasting stable boundary layers over land and ice, Front. Environ. Sci., 2, 41, doi:10.3389/fenvs.2014.00041, 2014.

Stull, R. B.: An Introduction to Boundary Layer Meteorology, Kluwer Academic Publisher, 666 pp., 1988.

Sukoriansky, S., Dikovskaya, N., and Galperin, B.: Transport of momentum and scalar in turbulent flows with anisotropic dispersive waves, Geophys. Res. Lett., 36, 3-7, doi:10.1029/2009GL038632, 2009.

Sun, J., Burns, S. P., Lenschow, D. H., Banta, R., Newsom, R., Coulter, R., Frasier, S., Ince, T., Nappo, C., Cuxart, J., Blumen, W., Lee, X., and Hu, X. Z.: Intermittent turbulence associated with a density current passage in the stable boundary layer, Bound.-Lay. Meteorol., 105, 199-219, doi:10.1023/A:1019969131774, 2002.

Sun, J., Lenschow, D. H., Burns, S. P., Miller, D., and Skelly, B.: Turbulence in Nocturnal Boundary Layers, Bound.-Lay. Meteorol., 110, 255-279, 2004.

Sun, J., Mahrt, L., Banta, R. M., and Pichugina, Y. L.: Turbulence Regimes and Turbulence Intermittency in the Stable Boundary Layer during CASES-99, J. Atmos. Sci., 69, 338-351, doi:10.1175/JAS-D-11-082.1, 2012.

Sun, J., Mahrt, L., Nappo, C., and Lenschow, D. H.: Wind and temperature oscillations generated by wave-turbulence interactions in the stably stratified boundary layer, J. Atmos. Sci., 72, 14841503, 2015a.

Sun, J., Nappo, C. J., Mahrt, L., Belusic, D., Grisogono, B., Stauffer, D. R., Pulido, M., Staquet, C., Jiang, Q., Pouquet, A., Yagüe, C., Galperin, B., Smith, R. B., Finnigan, J. J., Mayor, S. D., Svensson, G., Grachev, A. A., and Neff, W. D.: Review of WaveTurbulence Interactions in the Stable Atmospheric Boundary Layer, Rev. Geophys., doi:10.1002/2015RG000487, online first, 2015 b.
Terradellas, E., Morales, G., Cuxart, J., and Yagüe, C.: Wavelet methods: application to the study of the stable atmospheric boundary layer under non-stationary conditions, Dynam. Atmos. Oceans, 34, 225-244, 2001.

Torrence, C. and Compo, G. P.: A Practical Guide to Wavelet Analysis, B. Am. Meteorol. Soc., 79, 61-78, doi:10.1175/15200477(1998)079<0061:APGTWA>2.0.CO;2, 1998.

Udina, M., Soler, M. R., Viana, S., and Yagüe, C.: Model simulation of gravity waves triggered by a density current, Q. J. Roy. Meteorol. Soc., 139, 701-714, doi:10.1002/qj.2004, 2013.

van de Boer, A., Moene, A. F., Graf, A., Schüttemeyer, D., and Simmer, C.: Detection of Entrainment Influences on Surface-Layer Measurements and Extension of MoninObukhov Similarity Theory, Bound.-Lay. Meteorol., 152, 19-44, doi:10.1007/s10546-014-9920-8, 2014.

Van de Wiel, B. J. H., Moene, A. F., Hartogensis, O. K., De Bruin, H. A. R., and Holtslag, A. A. M.: Intermittent Turbulence in the Stable Boundary Layer over Land. Part III: A Classification for Observations during CASES-99, J. Atmos. Sci., 60, 2509-2522, doi:10.1175/15200469(2003)060<2509:ITITSB>2.0.CO;2, 2003.

van den Kroonenberg, A. and Bange, J.: Turbulent flux calculation in the polar stable boundary layer: Multiresolution flux decomposition and wavelet analysis, J. Geophys. Res.-Atmos., 112, 1-12, doi:10.1029/2006JD007819, 2007.

Van der Velde, I., Steeneveld, G., Wichers Schreur, B., and Holtslag, A.: Modeling and forecasting the onset and duration of severe radiation fog under frost conditions, Mon. Weather Rev., 138, 4237-4253, 2010.

Vercauteren, N. and Klein, R.: A clustering method to characterize intermittent bursts of turbulence and submeso motions interaction in the stable boundary layer, J. Atmos. Sci., 72, 1504-1517, doi:10.1175/JAS-D-14-0115.1, 2015.

Viana, S., Yagüe, C., and Maqueda, G.: Propagation and effects of a mesoscale gravity wave over a weakly-stratified nocturnal boundary layer during the SABLES2006 field campaign, Bound.-Lay. Meteorol., 133, 165-188, doi:10.1007/s10546-0099420-4, 2009.

Viana, S., Terradellas, E., and Yagüe, C.: Analysis of Gravity Waves Generated at the Top of a Drainage Flow, J. Atmos. Sci., 67, 3949-3966, doi:10.1175/2010JAS3508.1, 2010.

Viana, S., Yagüe, C., and Maqueda, G.: Vertical structure of the stable boundary layer detected by RASS-SODAR and in-situ measurements in SABLES 2006 field campaign, Acta Geophys., 60, 1261-1286, doi:10.2478/s11600-011-0072-7, 2012.

Vickers, D. and Mahrt, L.: The cospectral gap and turbulent flux calculations, J. Atmos. Ocean. Tech., 20, 660672, doi:10.1175/1520-0426(2003)20<660:TCGATF>2.0.CO;2, 2003.

Vindel, J. M. and Yagüe, C.: Intermittency of Turbulence in the Atmospheric Boundary Layer: Scaling Exponents and Stratification Influence, Bound.-Lay. Meteorol., 140, 73-85, doi:10.1007/s10546-011-9597-1, 2011.

Voronovich, V. and Kiely, G.: On the gap in the spectra of surfacelayer atmospheric turbulence, Bound.-Lay. Meteorol., 122, 6783, doi:10.1007/s10546-006-9108-y, 2007. 
Whiteman, C.: Mountain Meteorology: Fundamentals and Applications, Oxford University Press, 355 pp., New Jork, 2000.

Whiteman, C. D., Hoch, S. W., Hahnenberger, M., Muschinski, A., Hohreiter, V., Behn, M., Cheon, Y., Zhong, S., Yao, W., Fritts, D., Clements, C., Horst, T., Brown, W., and Oncley, S.: METCRAX 2006: Meteorological experiments in Arizona's Meteor crater, B. Am. Meteorol. Soc., 89, 1665-1680, 2008.
Yagüe, C., Viana, S., Maqueda, G., and Redondo, J. M.: Influence of stability on the flux-profile relationships for wind speed, $\Phi_{\mathrm{m}}$, and temperature, $\Theta_{\mathrm{h}}$, for the stable atmospheric boundary layer, Nonlin. Processes Geophys., 13, 185-203, doi:10.5194/npg-13185-2006, 2006. 